\title{
High-resolution DNA methylome reveals that demethylation enhances adaptability to continuous cropping comprehensive stress in soybean
}

Xilong Liang ${ }^{1}$, Xue Hou ${ }^{1}$, Jianying $\mathrm{Li}^{2}$, Yiqiang Han ${ }^{1}$, Yuxian Zhang ${ }^{1}$, Naijie Feng ${ }^{1}$, Jidao Du', Wenhui Zhang ${ }^{1}$, Dianfeng Zheng ${ }^{1 *}$ and Shumei Fang ${ }^{1 *}$

\begin{abstract}
Background: Continuous cropping stress involves such factors as biological barriers, allelopathic autotoxicity, deterioration of soil physicochemical properties, and soil fertility imbalance and is regarded as a kind of comprehensive stress limiting soybean yield and quality. Genomic DNA methylation is an important regulatory mechanism for plants to resist various environmental stresses. Therefore, it is especially worthwhile to reveal genomic methylation characteristics under stress and clarify the relationship between DNA methylation status and continuous cropping stress adaptability in soybean.

Results: We generated a genome-wide map of cytosine methylation induced by this kind of comprehensive stress in a tolerant soybean variety (Kang Xian 2, KX2) and a sensitive variety (He Feng, HF55) using whole-genome bisulfite sequencing (WGBS) technology. The expression of DNA demethylase genes was detected using real-time quantitative PCR (qRT-PCR). The functions of differentially methylated genes (DMGs) involved in stress response in biochemical metabolism and genetic information transmission were further assessed based on Gene Ontology (GO) annotation and Kyoto Encyclopedia of Genes and Genomes (KEGG) pathway analysis. The results showed that genomic DNA demethylation was closely related to continuous cropping comprehensive stress adaptability in soybean, which was further verified by the increasing expression of DNA demethylases ROS1 and DML. The demethylation of $\mathrm{mCpG}$ and $\mathrm{mCpHpG}$ (mCpApG preferred) contexts was more critical, which mainly occurred in gene-regulatory regions at the whole-chromosome scale. Moreover, this kind of stress adaptability may be related to various stress responders generated through strengthened glucose catabolism and amino acid and fatty acid anabolism, as well as fidelity transmission of genetic information.
\end{abstract}

Conclusions: Genomic DNA demethylation was closely associated with continuous cropping comprehensive stress adaptability, highlighting the promising potential of screening continuous cropping-tolerant cultivars by DNA methylation index and further exploring the application of DNA demethylases in soybean breeding.

Keywords: Continuous cropping comprehensive stress, DNA demethylation, Demethylase, Differentially methylated genes, Metabolism analysis, Soybean

\footnotetext{
* Correspondence: zdffnj@263.net; fangshumei520@126.com

${ }^{1}$ Heilongjiang Bayi Agricultural University, Daqing 163319, China

Full list of author information is available at the end of the article
}

(c) The Author(s). 2019 Open Access This article is distributed under the terms of the Creative Commons Attribution 4.0 International License (http://creativecommons.org/licenses/by/4.0/), which permits unrestricted use, distribution, and reproduction in any medium, provided you give appropriate credit to the original author(s) and the source, provide a link to the Creative Commons license, and indicate if changes were made. The Creative Commons Public Domain Dedication waiver (http://creativecommons.org/publicdomain/zero/1.0/) applies to the data made available in this article, unless otherwise stated. 


\section{Background}

Soybean (Glycine max [L.] Merr.), an agricultural product used for grain, cooking oil, fodder, and important industrial raw materials, is a continuous global staple crop $[1,2]$. Soybean plants are also important for soil fertility because they can fix atmospheric nitrogen through symbiosis with microbes in the rhizosphere [3]. However, due to salinization, desertification, the growing population, and other reasons, the area of arable land has decreased considerably over the last few decades $[4,5]$. The increasing demand for soy products and reduced cultivated land acreage have resulted in large areas of soybean coming under continuous cropping stress, especially in China [6-8]. For instance, the acreage devoted to soybean cultivation under continuous cropping accounted for more than $40 \%$ of the whole soybean planting area in 2012 in Heilongjiang Province, Northeast China [9]. After long-term continuous cropping, the crop may have poor growth due to continuous cropping obstacles including biological barriers, allelopathic autotoxicity of plants, the deterioration of soil physicochemical properties, and soil fertility imbalance, leading to low yields and poor quality [10-13]. Therefore, the obstacle of continuous cropping, a kind of comprehensive adversity, has been one of the bottlenecks restricting soybean yield increases and quality improvement.

When crops are exposed to stressful conditions, they will resort to various strategies to minimize the effects of stress, such as tolerance, resistance and avoidance. These strategies usually arise from changes in related gene expression $[14,15]$. DNA methylation is an indispensable epigenetic mechanism for normal plant development under adverse conditions that can result in stable alterations in gene expression without changes in the underlying DNA sequence [16-19].

In plants, DNA methylation commonly occurs at cytosine sites (where a methyl group is added at the $5^{\prime}$ position to form 5-methylcytosine) in either symmetrical $\mathrm{CpG}$ and $\mathrm{CpHpG}$ sequence contexts or asymmetrical $\mathrm{CpHpH}$ (where $\mathrm{H}$ is $\mathrm{A}, \mathrm{C}$, or $\mathrm{T}$ ) contexts $[20,21]$. Cytosine methylation in all sequence contexts is established through the RNA-directed DNA methylation (RdDM) pathway guided by 24-nt small interfering RNAs (siRNAs), in which the DNA methyltransferase Domains Rearranged Methyltransferase 2 (DRM2) is recruited to mediate de novo methylation. CpG and $\mathrm{CpHpG}$ methylations are maintained during subsequent rounds of DNA replication because of their symmetrical nature by DNA methyltransferase 1 (MET1) and chromomethylase 3 (CMT3), respectively, whereas asymmetrical $\mathrm{CpHpH}$ methylation is maintained by the RdDM pathway and chromomethylase 2 (CMT2) [22]. DNA methylation can also be removed by either passive DNA demethylation (failure to maintain methylation after replication) or active DNA demethylation (active removal by some enzymes). In plants, active DNA demethylation is mediated by members of the bifunctional DNA glycosidase subfamily, including Demeter (DME), Repressor of Silencing 1 (ROS1) and Demeter-like (DML). These enzymes can not only catalyse the hydrolysis of a glycosylic bond between the methylcytosine base and deoxyribose but also cleave the DNA backbone at abasic sites to form a single-nucleotide gap that will be filled with an unmethylated cytosine nucleotide by polymerase and ligase [21, 23-28].

By these DNA methylation or demethylation processes, DNA methylation can be dynamically regulated and maintained at a proper level in plants. When crop plants encounter environmental stresses, genomic DNA methylation levels will be changed to adapt to the challenge [29]. Diverse environmental stresses, such as cold, aluminium, herbicide, salt, drought stress, and nutrient stress, can induce heritable alteration in DNA methylation in plants [16, 30-34]. For example, cold stress causes strong genomewide DNA demethylation in maize seedlings, and the transcription of some demethylated genes increases in response to cold $[29,35]$. Salinity stress also induces DNA demethylation events in a tolerant Setaria italica L. cultivar, and the expression of stress-responsive genes is modulated [36]. However, in Medicago truncatula, salinity stress increases DNA methylation level as a stress-adaptive response [30]. Consequently, it is reasonable for us to assume that methylation alteration might be important for soybean plants to adapt to the comprehensive stress of continuous cropping. Up to now, there has been no report discussing the relationship between soybean continuous cropping adaptation and genomic DNA methylation.

In this study, we generated DNA methylomic maps of soybean varieties sensitive (He Feng 55, HF55) and tolerant (Kang Xian 2, KX2) to continuous cropping and examined their methylation changes induced by continuous cropping comprehensive stress using wholegenome bisulfite sequencing (WGBS) technology, which can accurately quantify whole-genome methylation at single-base resolution. The methylation levels of total $\mathrm{C}$, $\mathrm{CpG}, \mathrm{CpHpG}$, and $\mathrm{CpHpH}$ contexts; their distribution characteristics in the genome, on every chromosome and in specific gene regions; and their changes under continuous cropping comprehensive stress were revealed. Based on demethylation obtained in this work, the expression levels of DNA demethylase genes, including ROS1, DME and $D M L$, were detected by real-time quantitative PCR (qRT-PCR). Moreover, analysis of Gene Ontology (GO) annotation and Kyoto Encyclopedia of Genes and Genomes (KEGG) pathways of differentially methylated genes (DMGs) were performed to identify some genes involved in metabolic processes and fidelity transmission of genetic information associated with response to continuous cropping comprehensive stress. This work made it clear that genomic DNA demethylation was closely 
associated with continuous cropping comprehensive stress adaptability, reinforcing the understanding of DNA demethylation knowledge applied to continuous croppingtolerant cultivars breeding in soybean. To the best of our knowledge, this report is the first detailing the soybean genomic DNA methylation characteristics induced by continuous cropping comprehensive stress, corresponding demethylase activity, and possible metabolic mechanism and gene regulation caused by demethylation related to this kind of comprehensive stress adaptation.

\section{Results}

Bisulfite sequencing reveals that demethylation is closely related to continuous cropping resistance in soybean

Before analysing genomic methylation, we verified the different adaptabilities of sensitive HF55 and tolerant KX2 by investigating some morphological indexes including plant height, leaf area, stem and leaf dry weight, nodule number, nodule dry weight and chlorophyll content under continuous cropping comprehensive stress (Fig. 1a, Additional file 1: Table S1). On the basis of those data, bisulfite-seq analysis was performed to obtain base-pair-resolution DNA methylomes using an Illumina HiSeq 2000 and the WGBS method. The
WGBS library is the most comprehensive, highest-resolution method for detecting cytosine methylation $(5 \mathrm{mC})$ to reveal DNA methylation patterns and variation on a genome-wide scale, especially in the $\mathrm{CpHpG}$ and $\mathrm{CpHpH}$ contexts [37,38]. Cytosine methylation of non-CpG sites is extensive (more than $30 \%$ of the total $5 \mathrm{mC}$ ) in plant genomes $[39,40]$. Two cultivars were used to construct the WGBS libraries under continuous and non-continuous cropping conditions, and $33 \mathrm{~Gb}$ of sequence data per sample was generated, which covered more than $80 \%$ of sequences of each chromosome and gene region (Additional file 1: Figure S1, Table S2, Table S3).

In this work, the whole-genome methylation levels (the ratio of methylcytosine to cytosine) of each sample were first calculated. The results showed that the methylation ratio of tolerant KX2 and sensitive HF55 was 16.78 and $18.57 \%$ under non-continuous cropping conditions, respectively. In contrast, both cultivars displayed demethylation when they were exposed to continuous cropping stress. The degree of demethylation in KX2 was $18.77 \%$, which was higher than that in HF55 (8.35\%) (Fig. 1b). These results indicate that the tolerant soybean variety $\mathrm{KX} 2$ had a higher ability than the sensitive variety HF55 to adjust its DNA methylation
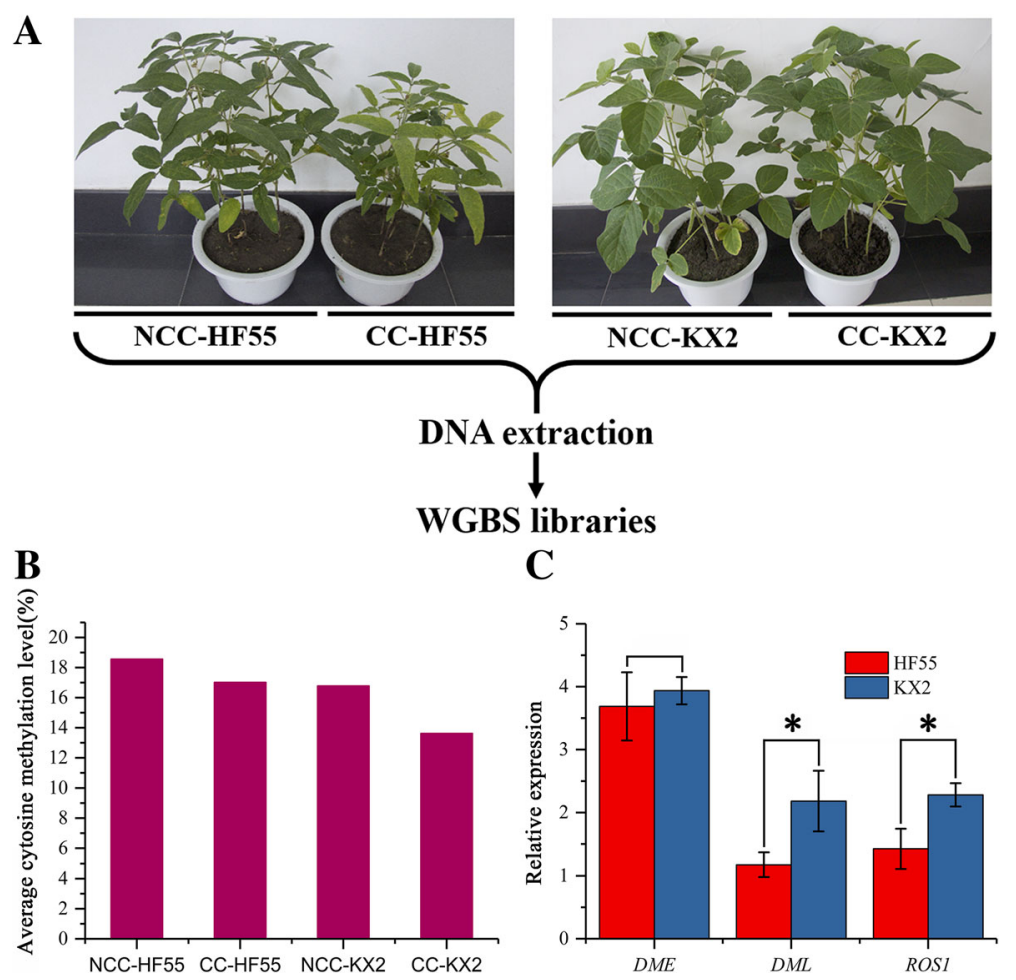

Fig. 1 DNA methylomes of continuous cropping sensitive and tolerant soybean varieties and expression analysis of some demethylase genes. a Soybean plant morphology of sensitive HF55 and tolerant KX2 under continuous cropping stress. The tolerant variety was verifiable by its phenotype 60 days after sowing. b Whole-genome methylation levels ( $\mathrm{mC} / \mathrm{C}$ ratios) in both varieties under continuous cropping comprehensive stress and the non-continuous cropping condition. c Expression analysis of the demethylase genes DME, DML and ROS1 under continuous cropping stress. (NCC: non-continuous cropping; CC: continuous cropping; HF55: He Feng 55; KX2: Kang Xian 2; same as below) 
levels upon exposure to continuous cropping stress, suggesting a link between the plasticity of DNA methylation and plant performance under continuous cropping stress.

To confirm the reliability of the above results, we further detected the expression of some important DNA demethylase genes, including $D M E, D M L$ and ROS1, by qRT-PCR. The results revealed that these genes were all up-regulated in both KX2 and HF55 under continuous cropping conditions (Fig. 1c). In particular, compared to the DML and ROS1 gene expression levels in HF55, those in KX2 were increased by 85.9 and $60.1 \%$, respectively (both $P<0.05$ ). Therefore, genomic DNA demethylation was enhanced by increasing DML and ROS1 expression, further indicating that demethylation was closely related to continuous cropping resistance of soybean.

\section{Demethylation of $\mathrm{mCpG}$ and $\mathrm{mCpHpG}$ contexts is more} important than that of the $\mathrm{mCpHpH}$ context for resisting continuous cropping comprehensive stress in soybean

The total DNA methylation levels and characteristics were further estimated at $\mathrm{CpG}$ and non-CpG $(\mathrm{CpHpG}$ and $\mathrm{CpHpH}$ ) sites. The level of $\mathrm{mCs}$ in $\mathrm{CpG}$ dinucleotides was 62.86 and $60.08 \%$ in HF55 and KX2, respectively, which was higher than that of $\mathrm{CpHpG}$ sequences (40.02\% in HF55 and $37.41 \%$ in $\mathrm{KX} 2$ ). $\mathrm{CpHpH}$ contexts only had a low methylation rate $(6.92 \%$ in HF55 and $5.65 \%$ in KX2) (Fig. 2a). However, interestingly, the percentages of total methylcytosine events that occurred in the three sequence contexts were not consistent with the DNA methylation levels. Among the contexts, $\mathrm{mCpHpH}$ accounted for the highest proportion (53.99 and $50.83 \%$ in HF55 and KX2, respectively) (Fig. 2b), while the proportion for $\mathrm{mCpG}$ was only 23.37 and $24.92 \%$ in HF55 and KX2, respectively, similar to that in CpHpG (22.64 and 24.45\% in HF55 and KX2). These contrasting results indicated that the methylation ratio in the $\mathrm{CpG}$ context was highest in the soybean genome, but in terms of the number of $\mathrm{mCs}$, the $\mathrm{mCpG}$ and $\mathrm{mCpHpG}$ contexts had much lower rates than the $\mathrm{mCpHpH}$ context. Moreover, $\mathrm{mCpG}$ and $\mathrm{mCpHpG}$ were mainly located in high methylation level (Fig. 2c).

Under continuous cropping stress, when genomic DNA demethylation occurred in both varieties, all the $\mathrm{CpG}$, $\mathrm{CpHpG}$ and $\mathrm{CpHpH}$ sites in tolerant $\mathrm{KX} 2$ were more demethylated than those in sensitive HF55 (Fig. 2a). Specifically, the methylation levels of $\mathrm{CpG}, \mathrm{CpHpG}$ and $\mathrm{CpHpH}$ sites decreased by $6.03,8.71$ and $0.95 \%$, respectively, in tolerant $\mathrm{KX} 2$, all of which were higher than those of sensitive HF55 (2.07, 1.90 and $0.77 \%$ at CpG, CpHpG and $\mathrm{CpHpH}$ sites, respectively). Therefore, the demethylation action of $\mathrm{mCpG}$ and $\mathrm{mCpHpG}$ contexts may be a more important factor than that of the $\mathrm{mCpHpH}$ context in resisting continuous cropping comprehensive stress in soybean.

Further, we analysed the relationship between $\mathrm{CpHpG}$ and $\mathrm{CpHpH}$ sequence contexts and methylation preference. We calculated the numbers of 9-mer sequences in which the $\mathrm{mC}$ was at the fourth position (Fig. 3). In non-methylation sequence contexts, CpTpG and CpApT were the most frequent, and there was no difference between HF55 and KX2. However, in the methylated $\mathrm{CpHpG}$ context, mCpApG was the most frequent in tolerant KX2. Under continuous cropping stress, the mCpApG ratio decreased, while the $\mathrm{mCpTpG}$ ratio became dominant, showing that mCpApG demethylation was more important than demethylation of other contexts for the continuous cropping adaptation of tolerant soybean. The methylated $\mathrm{CpHpH}$ context was very different from non-methylated sequences. The $\mathrm{CpT}$ dinucleotide was the most enriched upstream of $\mathrm{mC}$, followed by ApA, indicating that surrounding sequences may also be important in determining $\mathrm{CpHpH}$ methylation.

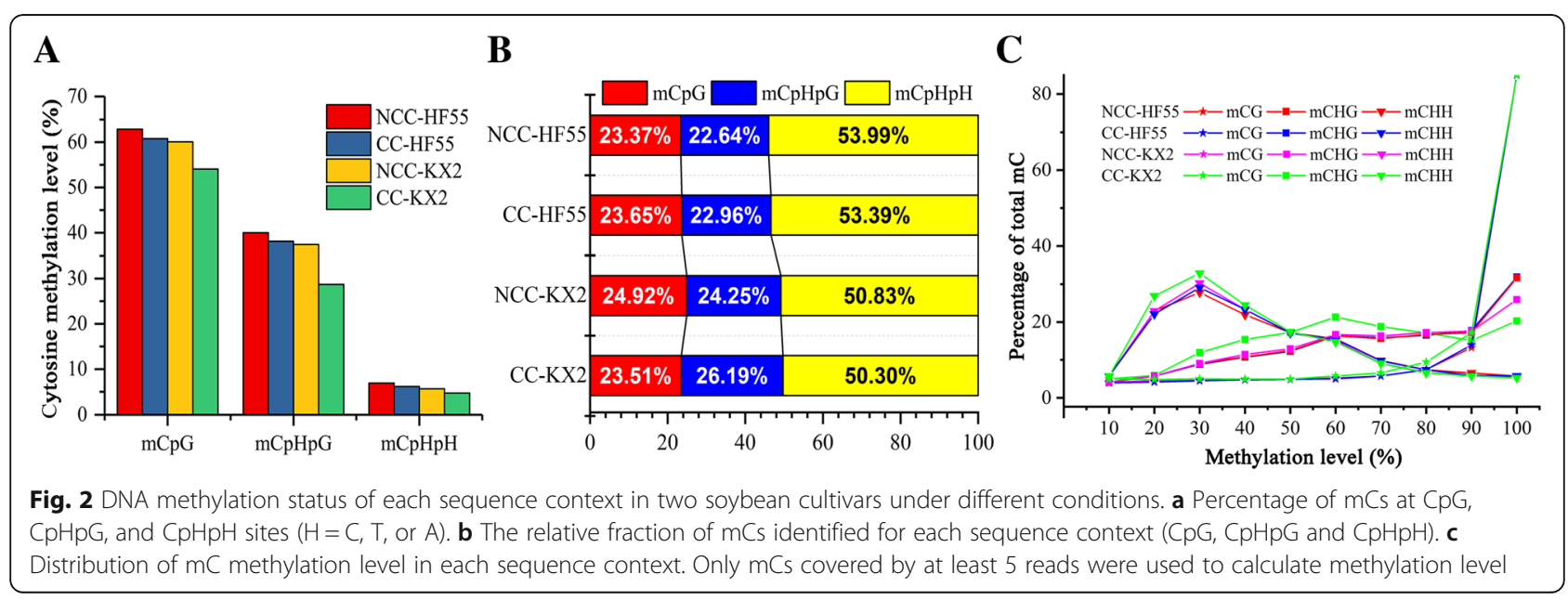




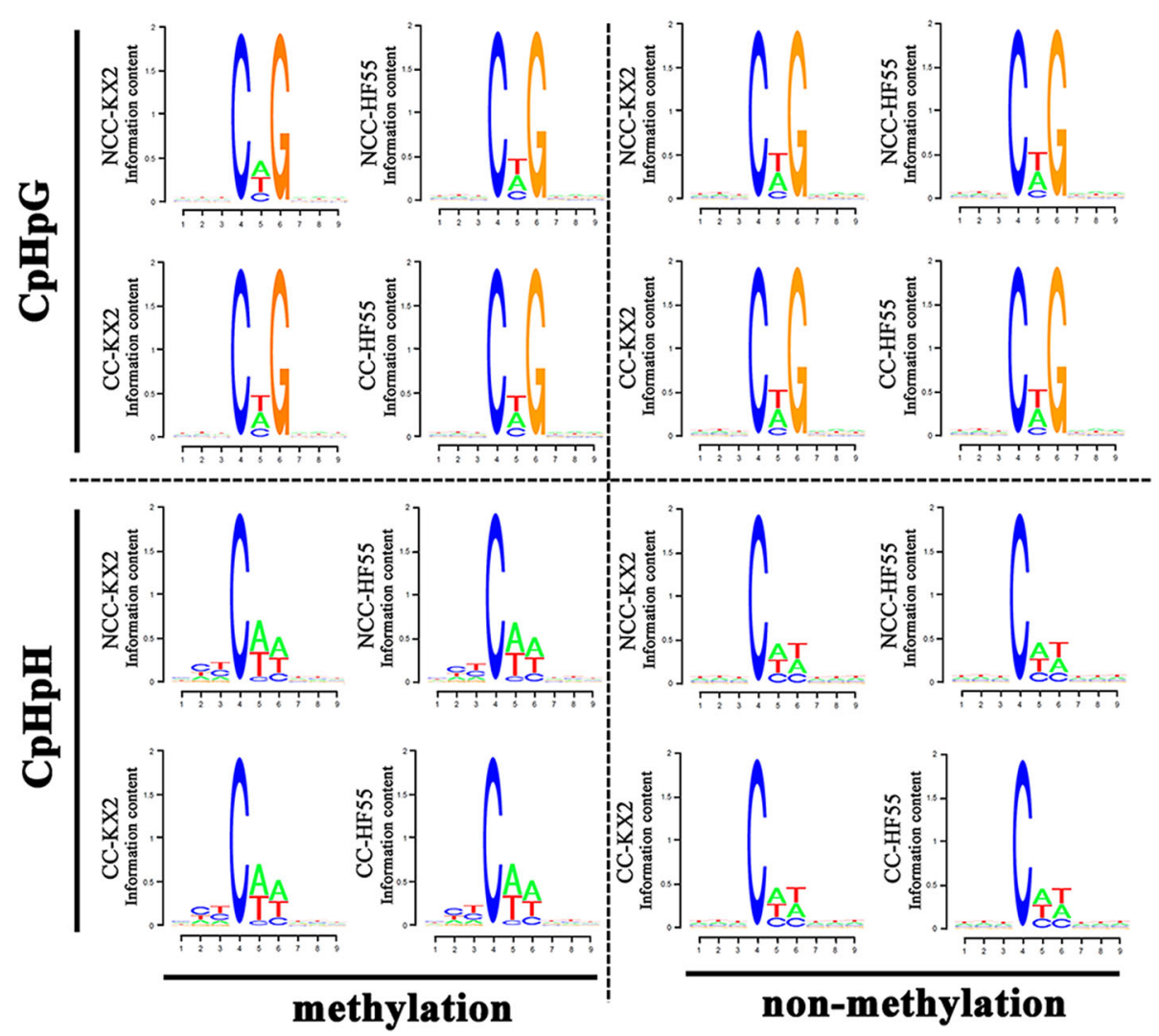

Fig. 3 Sequence preferences of methylated and non-methylated $\mathrm{CpHpG}$ and $\mathrm{CpHpH}$ contexts in two soybean cultivars under different conditions. The methylated cytosine is in the fourth position

\section{Soybean chromosomal DNA demethylation exhibits whole-scale regular characteristics under continuous cropping comprehensive stress}

We generated a set of methylation data for each of the twenty chromosomes in the four samples, which revealed the methylation characteristics at the chromosome level. As shown in Table 1, the total methylation levels of $\mathrm{C}$, $\mathrm{CpG}, \mathrm{CpHpG}$ and $\mathrm{CpHpH}$ sites were lowest on chromosome 13 and highest on chromosome 18 in both KX2 and HF55. Moreover, the methylation levels of all chromosomes in tolerant KX2 were lower than those in sensitive HF55. Under continuous cropping stress, cytosine (C, $\mathrm{CpG}, \mathrm{CpHpG}$ and $\mathrm{CpHpH}$ ) demethylation occurred on all chromosomes of both tolerant KX2 and sensitive HF55, and tolerant KX2 was more demethylated on all chromosomes than sensitive HF55. Specifically, total C demethylation ranged from 2.68 to 3.56 in $\mathrm{KX} 2$ but only from 1.15 to 1.8 in HF55, and chromosome 6 contained the most total $\mathrm{C}$ demethylation. In addition, in $\mathrm{KX} 2$, the demethylation of CpG and CpHpG contexts (5.22-7.61 and 6.8010.08 , respectively) on all chromosomes was much higher than that of the $\mathrm{CpHpH}$ context (0.85-1.02) under continuous cropping stress, and the $\mathrm{CpHpG}$ demethylation rate was the highest.
To characterize the distribution of all kinds of $\mathrm{C}$ methylation at the chromosome scale in greater detail, we generated dot plots of average $C$ methylation levels in sliding $100-\mathrm{kb}$ windows along each chromosome (Fig. 4, Additional file 1: Figures S2-1-S2-4). Moreover, we acquired the information for gene models and centromere location from the Soybean Genome Browser at SoyBase.org http://soybase.org/gbrowse/ cgi-bin/gbrowse/gmax1.01/. [41], and then matched the concrete methylation characteristics in the CpG, $\mathrm{CpHpG}$ and $\mathrm{CpHpH}$ contexts on all chromosomes. When comparing all kinds of cytosine methylation levels based on the density of genes, we found that DNA methylation was roughly negatively correlated with the density of genes. The density peaks of DNA methylation were most likely to be located in the regions containing few genes, which were mainly located in the pericentromeric region. In contrast, chromosome end regions containing more genes showed the opposite pattern. Further, most chromosomes had a higher methylation level in the telomeric region in the CpG context than in the other two contexts (Additional file 1: Figure S2), suggesting that the methylcytosine distribution at the chromosome level had regional characteristics. However, 
Table 1 Methylation characteristics at the chromosome level in sensitive and tolerant soybean varieties under different conditions

\begin{tabular}{|c|c|c|c|c|c|c|c|c|c|c|c|c|c|c|c|c|}
\hline \multirow[t]{2}{*}{ Chromosome } & \multicolumn{4}{|c|}{ NCC-HF55 } & \multicolumn{4}{|c|}{ CC-HF55 } & \multicolumn{4}{|c|}{ NCC-KX2 } & \multicolumn{4}{|c|}{$\mathrm{CC}-\mathrm{KX} 2$} \\
\hline & $C$ & $C G$ & $\mathrm{CHG}$ & $\mathrm{CHH}$ & $C$ & $C G$ & $\mathrm{CHG}$ & $\mathrm{CHH}$ & $C$ & $C G$ & $\mathrm{CHG}$ & $\mathrm{CHH}$ & $C$ & $C G$ & $\mathrm{CHG}$ & $\mathrm{CH}$ \\
\hline Gm01 & 20.44 & 69.95 & 49.21 & 7.99 & 18.89 & 67.44 & 47.15 & 7.16 & 18.71 & 67.61 & 46.86 & 6.60 & 15.48 & 61.18 & 36.83 & 5.61 \\
\hline Gm02 & 20.20 & 68.66 & 42.62 & 7.02 & 18.45 & 66.33 & 40.38 & 6.22 & 18.28 & 66.26 & 39.67 & 5.69 & 14.80 & 60.08 & 30.14 & 4.72 \\
\hline Gm03 & 18.91 & 64.94 & 42.91 & 7.18 & 17.29 & 62.48 & 40.82 & 6.38 & 17.40 & 63.90 & 41.79 & 5.92 & 14.30 & 57.80 & 32.71 & 4.98 \\
\hline Gm04 & 19.83 & 67.58 & 45.87 & 7.50 & 18.18 & 65.04 & 43.56 & 6.66 & 18.03 & 65.09 & 43.27 & 6.15 & 14.77 & 58.75 & 33.47 & 5.16 \\
\hline Gm05 & 19.16 & 64.97 & 41.15 & 6.89 & 17.53 & 62.61 & 38.97 & 6.09 & 17.37 & 62.54 & 38.58 & 5.61 & 14.01 & 55.98 & 29.27 & 4.63 \\
\hline Gm06 & 19.94 & 67.67 & 40.73 & 6.81 & 18.14 & 65.16 & 38.51 & 6.03 & 17.49 & 63.42 & 36.54 & 5.45 & 13.93 & 56.57 & 27.56 & 4.45 \\
\hline Gm07 & 18.79 & 64.92 & 40.52 & 6.81 & 17.11 & 62.29 & 38.31 & 6.06 & 17.06 & 62.71 & 38.34 & 5.60 & 13.82 & 56.20 & 29.48 & 4.68 \\
\hline Gm08 & 15.49 & 57.3 & 30.66 & 5.67 & 14.05 & 55.07 & 28.79 & 4.99 & 14.08 & 55.27 & 29.22 & 4.65 & 11.19 & 48.66 & 21.82 & 3.79 \\
\hline Gm09 & 18.51 & 63.41 & 41.90 & 7.03 & 16.80 & 60.48 & 39.36 & 6.19 & 16.48 & 60.05 & 38.67 & 5.64 & 13.29 & 53.44 & 29.36 & 4.66 \\
\hline Gm10 & 18.24 & 63.58 & 41.28 & 6.97 & 16.79 & 61.89 & 39.53 & 6.19 & 16.51 & 61.24 & 38.94 & 5.72 & 13.55 & 55.74 & 30.19 & 4.79 \\
\hline Gm11 & 17.81 & 59.99 & 38.69 & 6.79 & 16.20 & 57.57 & 36.44 & 5.98 & 16.01 & 57.50 & 36.24 & 5.50 & 12.84 & 51.14 & 27.13 & 4.49 \\
\hline Gm12 & 18.46 & 62.32 & 39.60 & 6.70 & 16.81 & 59.46 & 37.32 & 5.95 & 16.96 & 60.95 & 37.12 & 5.44 & 13.54 & 53.34 & 27.98 & 4.48 \\
\hline Gm13 & 13.95 & 50.66 & 27.08 & 5.28 & 12.51 & 47.87 & 25.23 & 4.65 & 12.34 & 48.08 & 24.94 & 4.24 & 9.66 & 41.56 & 18.14 & 3.39 \\
\hline Gm14 & 20.74 & 70.87 & 47.16 & 7.52 & 19.21 & 68.86 & 45.37 & 6.75 & 19.28 & 69.79 & 46.10 & 6.29 & 15.86 & 63.80 & 36.02 & 5.32 \\
\hline Gm15 & 17.54 & 62.82 & 39.20 & 6.86 & 15.85 & 59.60 & 36.88 & 6.05 & 16.10 & 61.52 & 37.04 & 5.59 & 13.04 & 54.99 & 28.09 & 4.62 \\
\hline Gm16 & 17.63 & 63.70 & 39.28 & 6.99 & 16.03 & 61.26 & 37.03 & 6.19 & 15.94 & 61.42 & 37.40 & 5.68 & 12.92 & 55.48 & 28.30 & 4.71 \\
\hline Gm17 & 17.68 & 58.43 & 36.47 & 6.41 & 16.53 & 57.88 & 35.56 & 5.79 & 15.51 & 55.05 & 32.76 & 5.23 & 12.49 & 49.35 & 24.67 & 4.26 \\
\hline Gm18 & 21.47 & 73.64 & 46.09 & 7.63 & 19.77 & 71.30 & 44.00 & 6.80 & 19.43 & 70.89 & 43.18 & 6.25 & 15.91 & 64.96 & 33.36 & 5.23 \\
\hline Gm19 & 18.99 & 66.08 & 43.02 & 7.26 & 17.45 & 63.90 & 40.97 & 6.49 & 18.05 & 66.44 & 42.78 & 6.11 & 14.97 & 61.22 & 33.45 & 5.15 \\
\hline Gm20 & 19.56 & 67.23 & 44.25 & 7.24 & 17.97 & 64.98 & 42.08 & 6.44 & 17.78 & 65.01 & 41.94 & 5.96 & 14.62 & 58.65 & 32.71 & 5.03 \\
\hline
\end{tabular}

we did not find obvious, large fluctuations when the methylation distribution was compared between continuous and non-continuous cropping conditions within the same variety, indicating that the demethylation caused by continuous cropping likely occurred at the wholechromosome scale.

\section{DNA demethylation induced by continuous cropping comprehensive stress mainly occurs in gene-regulatory regions}

To characterize the abundant $C$ methylation in the regions of the soybean genome, we used heat maps to represent the methylation distribution; $\mathrm{CpG}, \mathrm{CpHpG}$ and $\mathrm{CpHpH}$ density distribution; and the relationship between the two in the regions including the 3 '-UTR, 5 '-UTR, CDS, and upstream, downstream, intron and genome (Fig. 5). We found that in all regions, the densities of $\mathrm{CpG}, \mathrm{CpHpG}$ and $\mathrm{CpHpH}$ contexts increased in that order in the four samples. However, the number of high-methylation-level windows in upstream, downstream, 5'-UTR, 3'-UTR and genome decreased in the order of $\mathrm{CpG}, \mathrm{CpHpG}$ and $\mathrm{CpHpH}$ contexts. Moreover, continuous cropping comprehensive stress also decreased the number of high-methylation-level windows of $\mathrm{CpG}$ and $\mathrm{CpHpG}$ in these regions in $\mathrm{KX} 2$. Therefore, we compared the average methylation density of each context in specific regions. As shown in Table 2, higher $\mathrm{mC}$ densities were located upstream (5.75 in KX2 and 6.89 in HF55) and downstream (5.15 in KX2 and 6.09 in HF55) than in other regions, including the genebody, coding region (CDS), 3 '-UTR and 5 '-UTR. Under continuous cropping stress, total $\mathrm{C}$ methylation levels decreased by different degrees in all regions in both varieties, especially in KX2. The levels of upstream, downstream, $5^{\prime}$-UTR and 3 '-UTR were reduced more obviously, with reductions of $22.78,24.08,23.42$, and $21.15 \%$, respectively.

\section{Some vital metabolism processes and related DMGs in resisting continuous cropping comprehensive stress are revealed by DMG analysis}

To investigate differential methylation under continuous cropping stress, we identified differentially methylated regions (DMRs), which denote genomic regions of adjacent $\mathrm{CpG}$, CpHpG or $\mathrm{CpHpH}$ sites that are differentially methylated. DMRs were identified in windows containing at least five $\mathrm{CpG}$ (or $\mathrm{CpHpG}$ or $\mathrm{CpHpH}$ ) sites at the same position in two sample genomes. A total of 13,199 DMRs in tolerant KX2 and 4018 DMRs in sensitive HF55 were identified, and the hypomethylated proportion in KX2 (95.33\%) was much higher than that in HF55 (65.26\%) (Fig. 6a). A number of DMGs were identified in KX2 (4475) and HF55 (1951), 


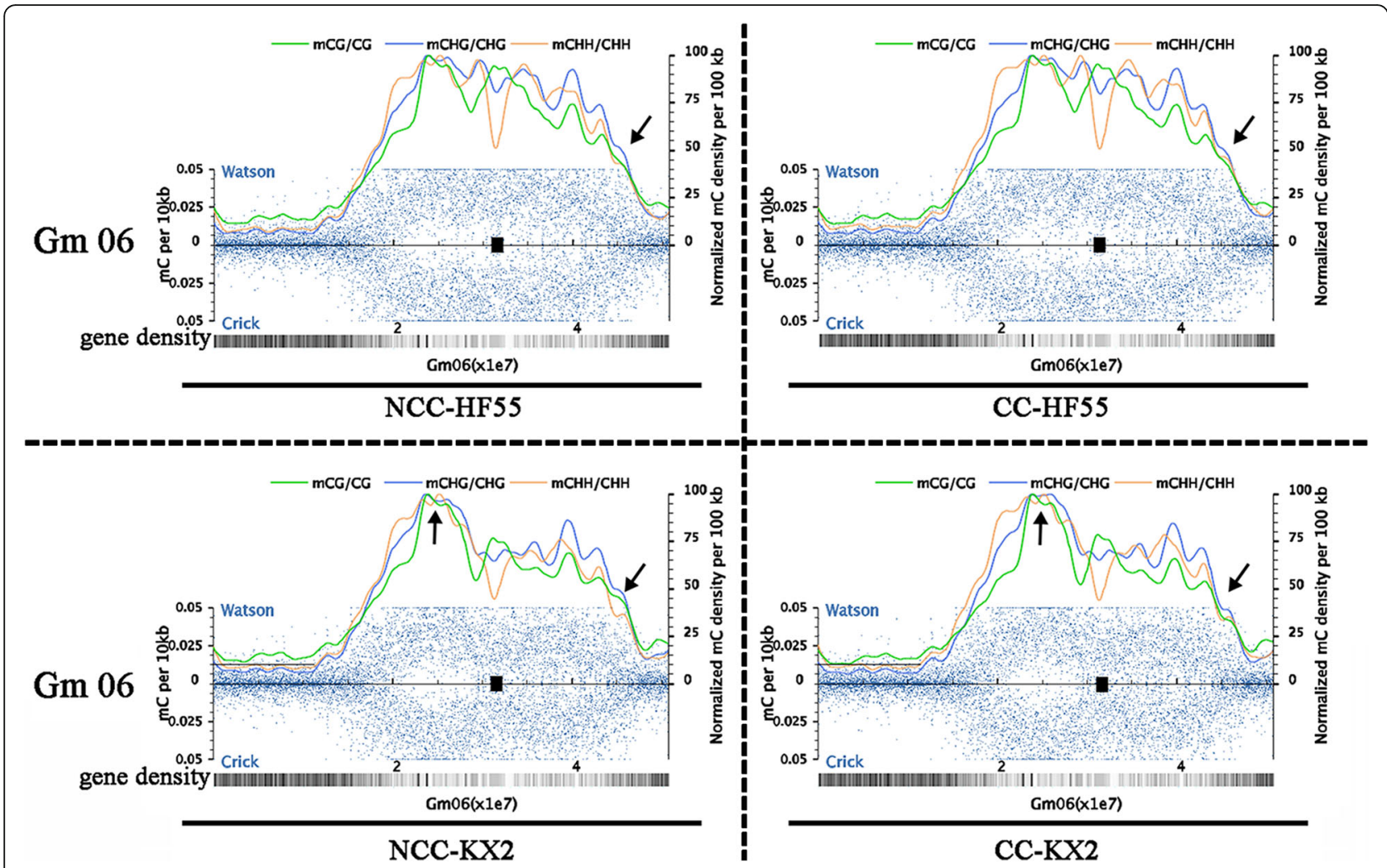

Fig. 4 Methylcytosine density throughout chromosome 6 in sensitive HF55 and tolerant KX2 under different conditions. Normalized methylated cytosine over total cytosine positions in 10-kb windows (blue dots, left axis) and normalized methylated CpG, $\mathrm{CpHpG}$, and $\mathrm{CpHpH}$ contexts in 100-kb windows (smoothed lines, right axis)

which consisted of hypomethylated genes and hypermethylated genes. In KX2, the number of hypomethylated genes was significantly higher (5.67 times) than that of hypermethylated genes under continuous cropping stress, whereas the numbers of hypo- and hypermethylated genes were not very different in HF55 (only 1.61 times) (Fig. 6b). GO annotation revealed that these DMGs are involved in diverse biological processes, such as metabolic processes, response to stimulus, signal, transcription, macromolecular complex and biological regulation (Fig. 6c).

Detailed pathway-based analyses showed that DMGs induced by continuous cropping comprehensive stress in tolerant KX2 are mainly involved in the processes of glucose, amino acid and fatty acid metabolism. As shown in Fig. 7 and Table 3, the $H K$, aceE, CS, $I D H$, and $O G D H$ genes encode hexokinase, pyruvate dehydrogenase E1 component, citrate synthase, isocitrate dehydrogenase and 2-oxoglutarate dehydrogenase E1 component, respectively, which are the key enzymes for glucose catabolism. Glucose catabolism can supply energy, reductants and some materials for amino acid and fatty acid synthesis. The amino acid metabolism-related genes $A L T, g l y A, c y s K$,
metE, DNMT1, and OTC encode alanine transaminase, glycine hydroxymethyltransferase, cysteine synthase A, 5-methyltetrahydropteroyltriglutamate-homocysteine methyltransferase, DNA (cytosine-5)-methyltransferase 1, and ornithine carbamoyltransferase, respectively. These enzymes may catalyse glutamate, glycine, cysteine, methionine, S-adenosylhomo-cysteine (SAH) and citrulline synthesis, which will contribute to the synthesis of polyamines (putrescine, spermidine, and spermine), GSH and phytochelatins (PCs). The GSR and FNR genes encode glutathione reductase (NADPH) and ferredoxin-NADP $(+)$ reductase, which can enhance GSH regeneration. GSH is actively resistant to stress because it is an important antioxidant, which can protect tissues from peroxide damage. Further, the genes $g l y A, G L D C$, and $A M T$ can catalyse one-carbon-unit N5,N10-methylene-THF synthesis from Ser and Gly, which are involved in nucleotide synthesis. The $A C A C A$ and $f a d B$ genes encode acetyl-CoA carboxylase and [acyl-carrier-protein] S-malonyltransferase, which will enforce the synthesis of fatty acids and their derivatives, such as jasmonic acid (JA), methyl JA (MeJA) and 12-oxo-10,15(Z) phytodienoic acid (OPDA). These compounds are all associated with plant resistance to biotic 


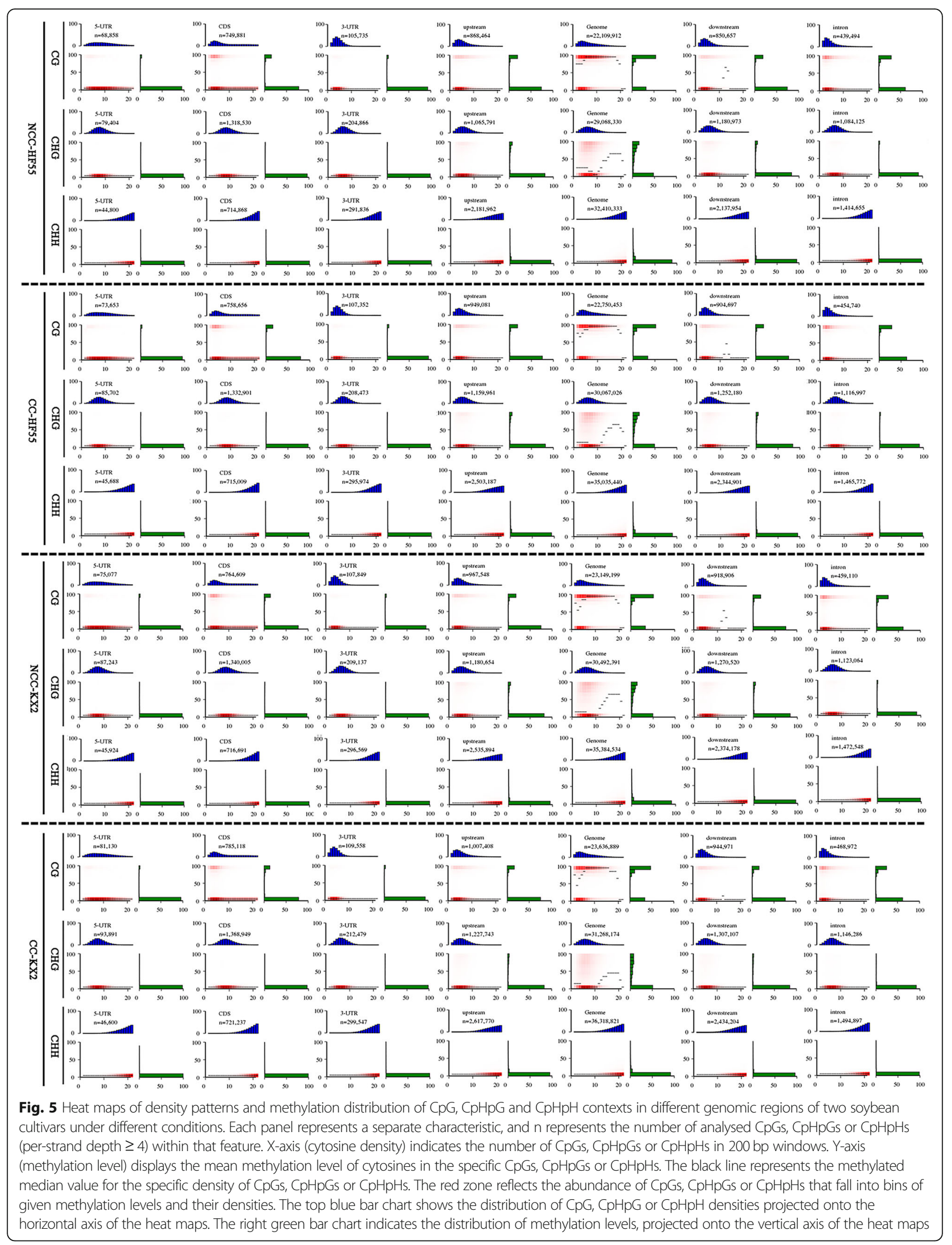


Table 2 Relative methylation density (mC/C ratios) in HF55 and KX2 throughout different gene-associated regions under different conditions

\begin{tabular}{|c|c|c|c|c|c|c|c|c|c|c|c|c|c|c|c|c|}
\hline \multirow[t]{2}{*}{ Regions } & \multicolumn{4}{|c|}{ NCC-HF55 } & \multicolumn{4}{|c|}{ CC-HF55 } & \multicolumn{4}{|c|}{ NCC-KX2 } & \multicolumn{4}{|c|}{ CC-KX2 } \\
\hline & $\bar{C}$ & $C G$ & $\mathrm{CHG}$ & $\mathrm{CHH}$ & $\bar{C}$ & $C G$ & $\mathrm{CHG}$ & $\mathrm{CHH}$ & $\bar{C}$ & $C G$ & $\mathrm{CHG}$ & $\mathrm{CHH}$ & $\bar{C}$ & $C G$ & $\mathrm{CHG}$ & $\mathrm{CH}$ \\
\hline 5'-UTR & 1.32 & 3.91 & 1.37 & 0.54 & 1.19 & 3.75 & 1.29 & 0.48 & 1.11 & 3.56 & 1.22 & 0.40 & 0.85 & 3.10 & 0.82 & 0.29 \\
\hline CDS & 3.33 & 16.40 & 2.68 & 0.79 & 3.19 & 16.99 & 2.57 & 0.71 & 3.09 & 15.94 & 2.48 & 0.62 & 2.60 & 15.61 & 1.65 & 0.4 \\
\hline 3'-UTR & 1.24 & 6.38 & 1.49 & 0.54 & 1.12 & 5.89 & 1.40 & 0.49 & 1.04 & 5.76 & 1.34 & 0.41 & 0.82 & 5.02 & 0.93 & 0.3 \\
\hline Upstream & 6.89 & 20.87 & 13.7 & 3.19 & 6.11 & 19.48 & 12.68 & 2.81 & 5.75 & 19.15 & 12.2 & 2.42 & 4.44 & 15.73 & 8.81 & 1.89 \\
\hline Genebody & 4.04 & 21.12 & 4.55 & 1.21 & 3.74 & 21.38 & 4.28 & 1.07 & 3.65 & 20.49 & 4.24 & 0.96 & 2.93 & 19.37 & 2.77 & 0.69 \\
\hline Downstream & 6.09 & 21.63 & 12.02 & 2.57 & 5.42 & 20.14 & 11.12 & 2.28 & 5.15 & 19.92 & 10.78 & 1.98 & 3.91 & 16.34 & 7.55 & 1.51 \\
\hline
\end{tabular}

and abiotic stresses. All of these genes were differentially demethylated in tolerant KX2 but not in sensitive HF55 under continuous cropping stress.

In addition, based on GO annotation, some stress-response genes are involved in the processes of DNA repair (MutL $\alpha$, XPD, and TFIIH4), RNA surveillance (PP2A and RNGTT), spliceosome formation (U5 snRNA) and protein processing in the endoplasmic reticulum (P97) (Fig. 8 and Table 4). These processes are closely related to plant adaptability to stress. Moreover, these DMGs involved in metabolism processes and fidelity transmission of genetic information were characterized with demethylation of $\mathrm{CpG}$ and $\mathrm{CpHpG}$ contexts (Table 3 and Table 4).

\section{Discussion}

DNA methylation changes in plant genomes can generate novel and heritable phenotypic variation, which will improve tolerance, resistance and adaptation to poor environments by influencing gene expression [42, 43]. The striking phenotypic difference between tolerant KX2 and sensitive HF55 prompted us to profile their methylomes in response to continuous cropping stress. The highresolution analysis provided unique insight into the plasticity of DNA methylation in response to the comprehensive stress of continuous cropping. We observed that the total methylation ratios of tolerant $\mathrm{KX} 2$ and sensitive HF55 were 16.78 and $18.57 \%$, respectively, which are lower than those of both maize (20\%) [35] and rice (24.3\%) [44] but more than three times that of Arabidopsis (5.26\%) [45], indicating specific methylation levels among diverse plant species [29]. Lukens and Zhan reported that a moderate cytosine methylation level played an important role in maintaining genome stability, contributing to the silencing of transposable elements and controlling the transcription of some genes in plants [42]. In this study, we found that continuous cropping comprehensive stress induced genomic DNA demethylation in soybean. The tolerant variety $\mathrm{KX} 2$ was able to

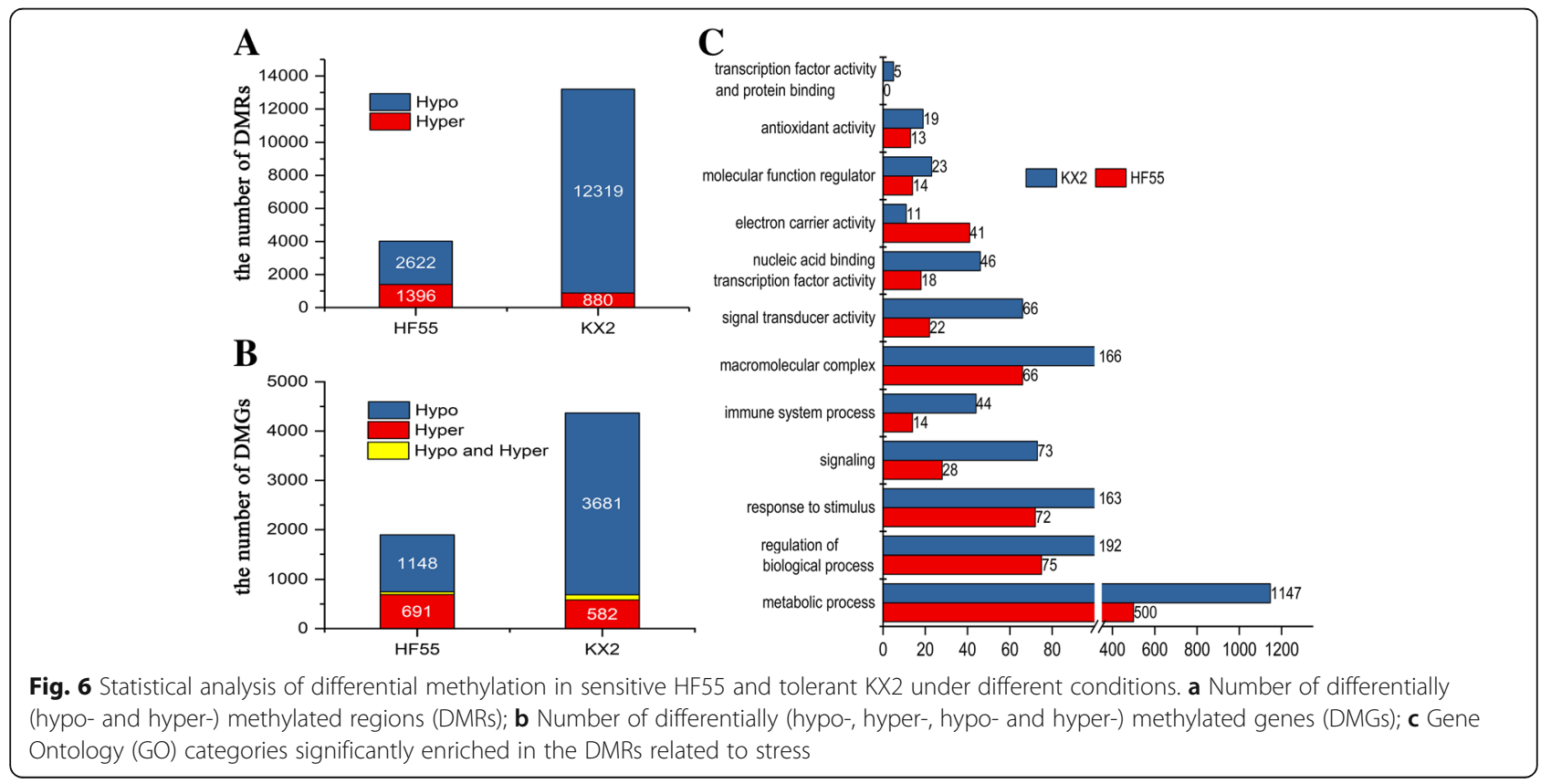




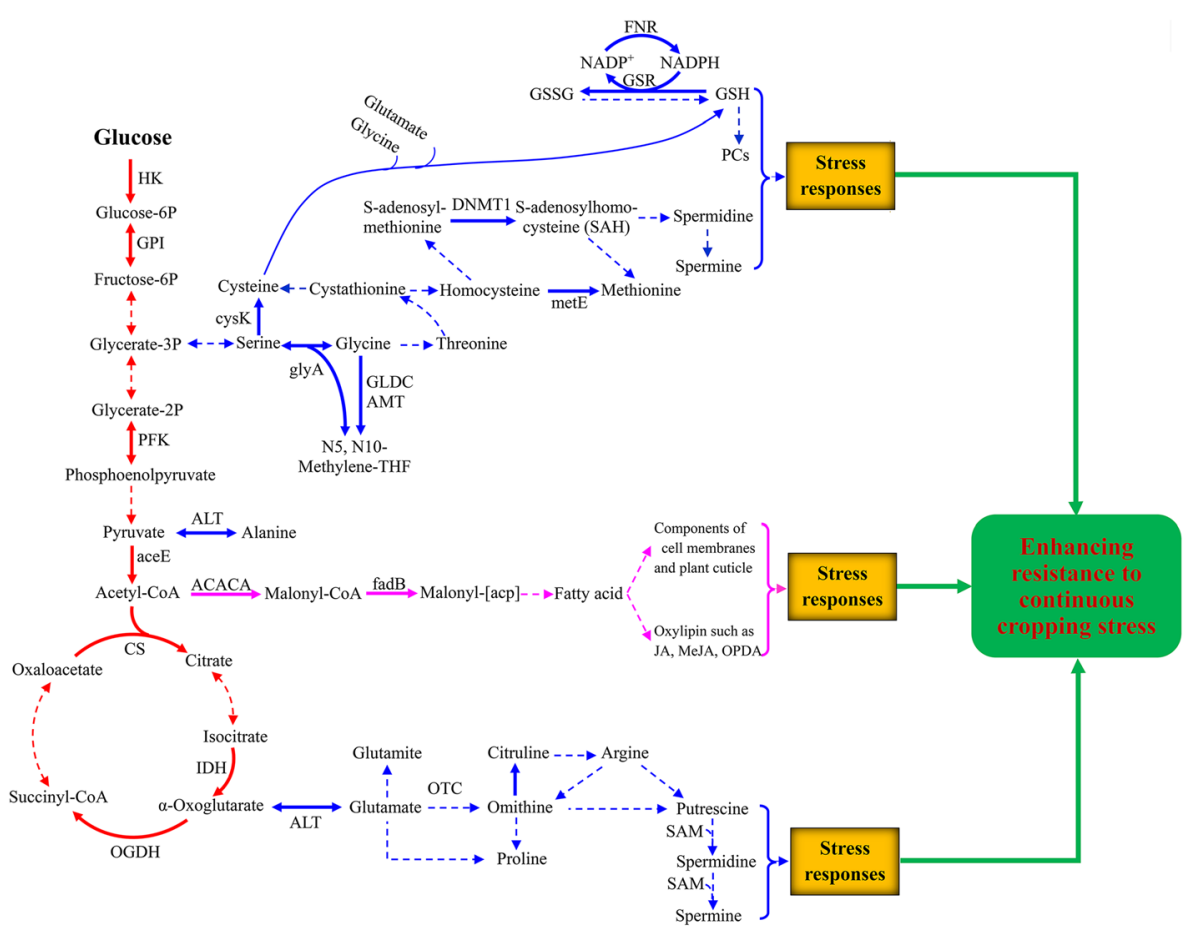

[Sugar catabolism Amino acid metabolism and lipid metabolism] Resistance

Promoting the formation of resistant substances by strengthening sugar catabolism

Fig. 7 Primary metabolic pathways that respond to continuous cropping comprehensive stress. Solid lines represent one-step reactions and corresponding differentially demethylated enzyme genes. Dotted lines indicate that enzyme genes are not differentially demethylated and/or multi-step reactions. HK: hexokinase; GPI: glucose-6-phosphate isomerase; PFK: 6-phosphofructokinase 1; aceE: pyruvate dehydrogenase E1 component; CS: citrate synthase; IDH: isocitrate dehydrogenase; OGDH: 2-oxoglutarate dehydrogenase E1 component; ALT: alanine transaminase; cysK: cysteine synthase A; glyA: glycine hydroxymethyltransferase; GLDC: glycine dehydrogenase; AMT: aminomethyltransferase; metE: 5-methyltetrahydropteroyltriglutamatehomocysteine methyltransferase; DNMT1: DNA (cytosine-5)-methyltransferase 1; OTC: ornithine carbamoyltransferase; ACACA: acetyl-CoA carboxylase; fabD: [acyl-carrier-protein] S-malonyltransferase; GSR: glutathione reductase (NADPH); FNR: ferredoxin-NADP(+) reductase; PCs: Phytochelatins; JA: jasmonic acid; MeJA: methyl JA; OPDA: 12-oxo-10,15(Z) phytodienoic acid

rapidly reduce its DNA methylation level (by 18.77\%), while the sensitive variety HF55 showed a low ability to adjust its DNA methylation level (decrease of 8.35\%) upon exposure to continuous cropping stress, suggesting a link between the plasticity of DNA methylation and plant tolerance performance. A decrease in DNA methylation level will cause the activation of some genes, which will enhance the expression of stress-resistant proteins [32, 46-48]. Therefore, we infer that the tolerant variety $\mathrm{KX} 2$ can better adapt to the comprehensive stress of continuous cropping than the sensitive variety HF55 through further demethylation. This finding is in agreement with earlier results on DNA demethylation in response to adverse conditions, such as biotic stress [32, 49, 50], salt stress [51] and Fe deficiency [52]. The reason is that chromatin demethylation and the relaxation of its structure could serve as a transcriptional switch for many stress-regulated genes [15]. However, hypermethylation of cytosine residues has also been uncovered in pea root tips in response to water deficit stress [53] and in tobacco [54] and potato [55] cell cultures in response to osmotic stress. Therefore, epigenetic change at the DNA methylation level, whether hypomethylation or hypermethylation, plays an important role in plant adaptation to environmental stress and growth and development. Importantly, though, distinct epigenetic responses occur between different plants and in response to different stress stimuli.

DNA methylation in plants occurs in three cytosine contexts including $\mathrm{CpG}, \mathrm{CpHpG}$ and $\mathrm{CpHpH}$ (H replacing $\mathrm{A}, \mathrm{C}$ or $\mathrm{T})[56,57]$, and it appears to have various functions, including regulating the expression of some genes, reprogramming and imprinting [58]. The cytosine methylation patterns result not only from the establishment and maintenance of $\mathrm{mCs}$ but also from demethylation [59]. The removal of methylcytosine can be accomplished via passive or active processes. In passive demethylation, the $\mathrm{mCs}$ are 
Table 3 Stress-induced DMGs involved in metabolism processes and their demethylated types in soybean

\begin{tabular}{|c|c|c|c|}
\hline Abbreviation & Full name of enzyme & Gene name in Soybean & DMG Type \\
\hline HK & hexokinase [EC:2.7.1.1] & Glyma07g12190 & CG \\
\hline GPI & glucose-6-phosphate isomerase [EC:5.3.1.9] & Glyma19g02031 & $\mathrm{CHG}$ \\
\hline PFK & 6-phosphofructokinase 1 [EC:2.7.1.11] & Glyma18g22780 & CHG \\
\hline aceE & $\begin{array}{l}\text { pyruvate dehydrogenase E1 component } \\
\text { [EC:1.2.4.1] }\end{array}$ & $\begin{array}{l}\text { Glyma07g03930; } \\
\text { Glyma17g03560 }\end{array}$ & $\mathrm{CHG} ; \mathrm{CHG}$ \\
\hline CS & citrate synthase [EC:2.3.3.1] & Glyma18g12393 & $\mathrm{CHG}$ \\
\hline $\mathrm{IDH}$ & isocitrate dehydrogenase [EC:1.1.1.42] & Glyma08g17080 & $\mathrm{CHG}$ \\
\hline $\mathrm{OGDH}$ & $\begin{array}{l}\text { 2-oxoglutarate dehydrogenase E1 } \\
\text { component [EC:1.2.4.2] }\end{array}$ & Glyma17g03560 & $\mathrm{CG} / \mathrm{CHG} ; \mathrm{CHG}$ \\
\hline ACACA & $\begin{array}{l}\text { acetyl-CoA carboxylase } \\
\text { [EC:6.4.1.2 6.3.4.14 2.1.3.15] }\end{array}$ & Glyma04g11550 & $\mathrm{CHG}$ \\
\hline fabD & $\begin{array}{l}\text { [acyl-carrier-protein] S-malonyltransferase } \\
\text { [EC:2.3.1.39] }\end{array}$ & Glyma18g06500 & CG \\
\hline ALT & alanine transaminase [EC:2.6.1.2] & Glyma02g04320 & CG \\
\hline glyA & $\begin{array}{l}\text { glycine hydroxymethyltransferase } \\
\text { [EC:2.1.2.1] }\end{array}$ & Glyma18g27710 & $\mathrm{CHG}$ \\
\hline GLDC & glycine dehydrogenase [EC:1.4.4.2] & Glyma17g34690 & CG \\
\hline AMT & aminomethyltransferase [EC:2.1.2.10] & Glyma15g11590 & CG \\
\hline cysk & cysteine synthase A [EC:2.5.1.47] & $\begin{array}{l}\text { Glyma02g15640; } \\
\text { Glyma15g41600 }\end{array}$ & $\mathrm{CHG} ; \mathrm{CHG}$ \\
\hline metE & $\begin{array}{l}\text { 5-methyltetrahydropteroyltriglutamate- } \\
\text { homocysteine methyltransferase [EC:2.1.1.14] }\end{array}$ & Glyma17g23730 & $\mathrm{CHG}$ \\
\hline DNMT1 & $\begin{array}{l}\text { DNA (cytosine-5)-methyltransferase } 1 \\
\text { [EC:2.1.1.37] }\end{array}$ & $\begin{array}{l}\text { Glyma11g08861; } \\
\text { Glyma01g01120; } \\
\text { Glyma16g17720 }\end{array}$ & $\mathrm{CHG} ; \mathrm{CG} ; \mathrm{CG} / \mathrm{CHG}$ \\
\hline OTC & ornithine carbamoyltransferase [EC:2.1.3.3] & Glyma06g03361 & CG \\
\hline GSR & glutathione reductase (NADPH) [EC:1.8.1.7] & Glyma02g08180 & $\mathrm{CHG}$ \\
\hline FNR & ferredoxin-NADP(+) reductase [EC 1.18.1.2] & Glyma08g17080 & $\mathrm{CHG}$ \\
\hline
\end{tabular}

replaced with unmethylated cytosines during DNA replication, while in active demethylation, the methyl mark is removed by $5 \mathrm{mC}$ glycosylases such as DME, DML and ROS1. These enzymes, possessing both glycosylase (base excision) and AP lyase activity that are directed towards $\mathrm{mCs}$, are involved in base excision repair [60]. In our work, the relative expression levels of DML and ROS1 in KX2 were significantly higher than those in HF55 under continuous cropping stress. The high expression of these enzymes should be one of the factors causing extensive demethylation in genomic DNA [25]. Active DNA demethylation is important in maintaining epigenomic plasticity to enable efficient response to environmental stresses in a timely manner $[17,59]$. These results further confirm that the DNA demethylation is related to the resistance of soybean to the continuous cropping comprehensive stress. Therefore, how to apply demethylase in plant resistance to this kind of stress should be researched in the future.

Cytosine bases of the nuclear genome in higher plants are often extensively methylated $[40,56]$. In this work, we described the profile of DNA methylation density for each of the 20 chromosomes in 100-kb windows. Interestingly, chromosome end regions showed lower DNA methylation density, where gene density was high, suggesting that cytosine methylation occurred in the intergenic regions. Figure 4 and Additional file 1: Figure S2(-1,-2,-3,-4) also show low methylation density in the telomeric regions. These results are in agreement with previous reports on Arabidopsis telomere methylation. Vaquero-Sedas et al. found that Arabidopsis telomeres have lower levels of DNA methylation than internal transcribed spacers or subtelomeres [61]. Later, VegaVaquero et al. confirmed that DNA methylation is indeed absent in Arabidopsis telomeres based on experiments on high telomeric C-rich strand production efficiencies and methylation-dependent restriction enzyme analyses [62]. In addition, they pointed out that the degree of telomeric DNA denaturation during the process of sequencing or the formation of telomeric C-rich strand secondary structures such as the i-motif might cause the overestimation of telomeric methylation $[63,64]$. Schoeftner and Blasco 


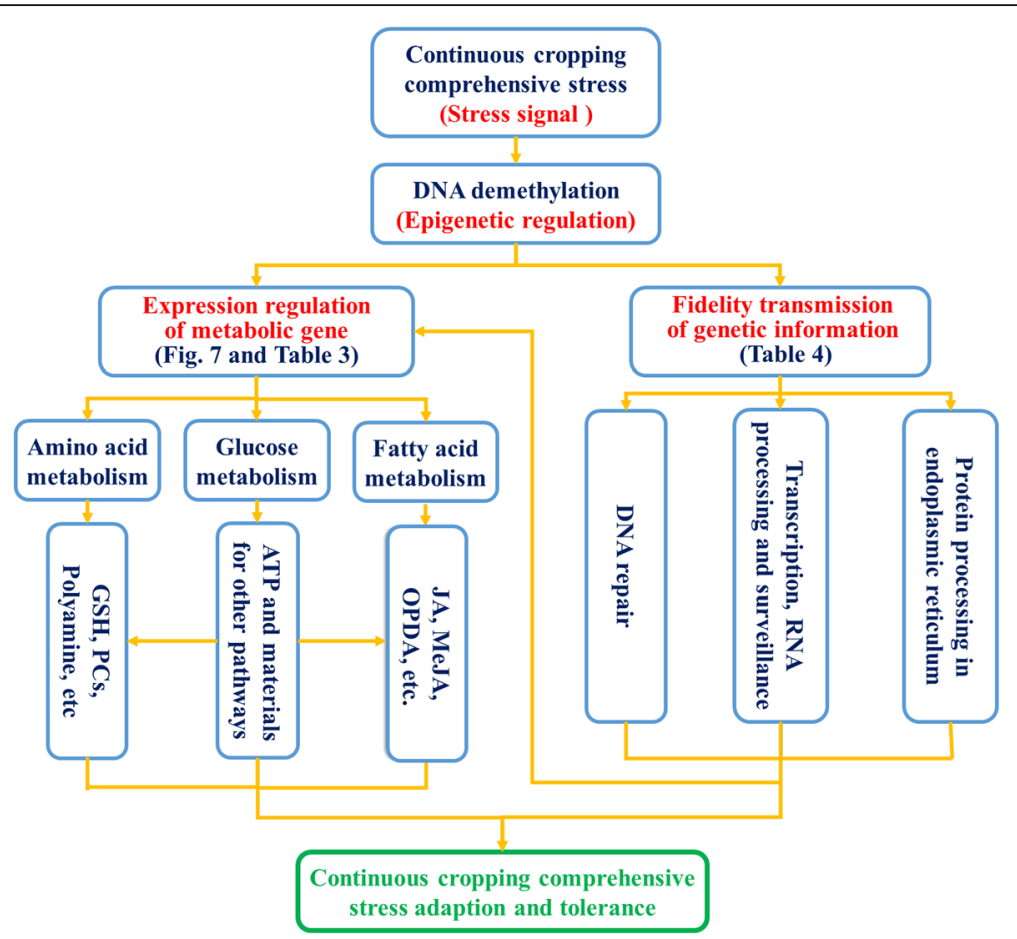

Fig. 8 Schematic showing the points at which soybean copes with continuous cropping comprehensive stress by metabolic and genetic regulation resulting from DNA demethylation. The continuous cropping stress signal resulted in DNA demethylation. Some metabolic and genetic processes were modified, causing the plants to adapt to the stress in the continuous cropping environment

also considered that conserved telomeric repeats remained unmethylated because the asymmetric target units (CCCT AAA) $\mathrm{n}$ in plants lack methylable cytosines [65].

In mammals, DNA methylation predominantly occurs at cytosines in $\mathrm{CpG}$ sequences, while in plants, methylation of $\mathrm{CpH}$ sequences $(\mathrm{CpHpG}$ and $\mathrm{CpHpH}$, where $\mathrm{H}$ can be $\mathrm{A}, \mathrm{C}$ or $\mathrm{T}$ ) is also present and involved in epigenetic regulation and gene expression [66, 67]. Therefore, detecting the context proximal to sites of $\mathrm{CpH}$ methylation is essential for determining whether stresses caused some enrichments of particular local sequences and basal changes, as previously reported in Arabidopsis DNA methylomes $[45,68]$. No local sequence enrichment was observed upstream of $\mathrm{mCpHpG}$ sites, while the base following the methylcytosine tended to be adenine or thymine (mCpA/TpG) (Fig. 3). This trend is consistent with a nearest-neighbour analysis of wheat germ DNA that found a higher level in mCpApG and mCpTpG sites than in $\mathrm{mCpCpG}$ sites [69]. Further, we found that the base preference following methylcytosine in $\mathrm{mCpHpG}$ changed

Table 4 DMGs involved in fidelity transmission of genetic information within GO annotation and their demethylated types in soybean

\begin{tabular}{|c|c|c|c|c|}
\hline Process involved & Pathway involved & Transcript name & Protein name & DMG Type \\
\hline \multirow[t]{3}{*}{ DNA repair } & \multirow[t]{2}{*}{ Nucleotide excision repair } & Glyma16g28290 & XPD & CG \\
\hline & & Glyma07g31520 & $\mathrm{TFIIH} 4$ & CG \\
\hline & Mismatched repair & Glyma10g02390 & MutLa & CG \\
\hline \multirow[t]{5}{*}{ RNA biosynthesis } & \multirow[t]{2}{*}{ Basal transcription factors } & Glyma07g31520 & $\mathrm{TFIIH} 4$ & CG \\
\hline & & Glyma16g28290 & XPD & CG \\
\hline & Spliceosome & Glyma17g11410 & Snu114 & CHG \\
\hline & \multirow[t]{2}{*}{ RNA surveillance } & Glyma03g34240 & PP2A & CHG \\
\hline & & $\begin{array}{l}\text { Glyma03g14700; } \\
\text { Glyma01g27240 }\end{array}$ & RNGTT & $\mathrm{CG} ; \mathrm{CHG}$ \\
\hline Protein biosynthesis & Protein processing in endoplasmic reticulum & $\begin{array}{l}\text { Glyma06g19000; } \\
\text { Glyma03g33990; } \\
\text { Glyma12g30060 }\end{array}$ & P97 & CG; CG; CHG \\
\hline
\end{tabular}


under continuous cropping comprehensive stress in tolerant $\mathrm{KX} 2$, and $\mathrm{mCpTpG}$ became more common than mCpApG. Therefore, we infer that mCpApG sequences are more easily demethylated than other sequences under continuous cropping comprehensive stress in tolerant $\mathrm{KX}$ 2, which resulted in the decrease in the percentage of $\mathrm{mCpApG}$ and thus the dominance of mCpTpG. This process may regulate gene expression, but further research is necessary to clarify the role of $\mathrm{CHG}$ demethylation, as reviewed by Pelizzola and Ecker [70]. In addition, similar to the $\mathrm{mCpHpH}$ context, $\mathrm{mC}$ also tended to be followed by an $\mathrm{A}$ or a $\mathrm{T}$. This result is consistent with data from mammalian and Arabidopsis genomes indicating that $\mathrm{mCpT}$ and $\mathrm{mCpA}$ sequences are more frequent than $\mathrm{mCpC}$ sequences $[45,68,71]$.

DMRs, GO annotation and KEGG pathway analysis indicated that some DMGs in response to continuous cropping comprehensive stress are involved in some vital metabolic processes (Fig. 6). HK, aceE, CS, IDH, and $O G D H$ are key genes for glucose catabolism, which is the central metabolic pathway in all organisms. This pathway produces ATP, reductants and some materials for amino acid and fatty acid synthesis. Additionally, glucose catabolism is directly involved in adaptation of plants to environmental stresses, such as nutrient limitation, drought, low-temperature and osmotic stress [72]. The ALT, glyA, cysK, metE, DNMT1, and OTC gene products catalyse the synthesis of some important amino acids such as SAH, methionine, cysteine, glycine, glutamate and citrulline. These amino acids are necessary for the biosynthesis of some defence compounds, such as GSH, polyamines and PCs. The GSR and FNR gene products also enhance GSH regeneration. GSH has many distinct functions in plant stress defence, including removing harmful $\mathrm{H}_{2} \mathrm{O}_{2}$ to protect tissues from peroxide damage, controlling gene expression linked to the redox state of cells and being an important reducing cofactor of many enzymes related to reactive oxygen species (ROS) detoxification [73-75]. Some researchers reported that plants exposed to salicylic acid (SA) (which plays a key role in plant stress tolerance) and abscisic acid (ABA) (which is related to environmental stress adaptation) exhibited higher GSH concentrations and glutathione reductase (GR) activity than those without such exposure, which further certifies the relationship between GSH content and stress defence [76-78]. Moreover, GSH is also related to the synthesis of PCs, which is involved in stress response [78]. In addition, SAH is the product catalysed by DNMT1 in the S-adenosylmethionine/ homocysteine cycle. Fuso and $\mathrm{Lu}$ et al. reported that $\mathrm{SAH}$ is a strong DNA methyltransferase inhibitor that will reinforce genomic DNA hypomethylation $[79,80]$. Polyamine synthesis is an important nitrogen-metabolizing pathway regulating ammonia metabolism and organic nitrogen balance in plant cells [81-85]. During the process of polyamine generation, some intermediates, such as nitric oxide (NO) and $\gamma$-aminobutyric acid (GABA), can also be produced $[86,87]$. Polyamines, NO and GABA all play important roles in the regulation of plant development and as signal molecules mediating some responses to biotic and abiotic stressors, including pathogens, heavy metal, drought and salt [85, 88-91]. The $A C A C A$ and $f a d B$ genes contribute to fatty acid synthesis. Fatty acids not only are crucial components of cellular membranes, suberin, and cutin waxes, but also are important for the remodelling of membrane fluidity, which will increase plant resistance to drought, physical injury and infection by pathogenic microorganisms [92, 93]. Moreover, fatty acids are the materials for the synthesis of substances related to environmental stress adaptation, including JA, MeJA and OPDA, which are also associated with plant basal immunity and responses to pathogens [94, 95]. Therefore, based on the analysis above and our results, we think these substances are involved in the response to continuous cropping comprehensive stress, including biological barriers, allelopathic autotoxicity, the deterioration of soil physicochemical properties and soil fertility imbalance, and DNA demethylation may be the source inducing these complex resistance mechanisms.

The stable inheritance of DNA genetic information, RNA transcription and correct protein synthesis are vital molecular processes for ensuring cell-cycle progression and various biofunctions, all of which are involved in plant growth and stress response [96-99]. In this work, we observed that some DMGs in tolerant KX2 were involved in continuous cropping comprehensive stress responses (GO annotation). These genes took part in the processes of DNA repair, transcription, RNA splicing, RNA surveillance, and protein processing in the endoplasmic reticulum (Fig. 8, Table 4). These molecular processes are capable of adjusting the levels of mRNA and functional proteins that will alter some metabolic processes and thus participate in the stress response [99-101]. Consequently, resistant plants can tolerate complicated environmental stresses more efficiently and effectively through metabolic networks and fidelity transmission of genetic information caused by DNA methylation changes, enhancing their adaptability under continuous cropping comprehensive stress (both biotic and abiotic stresses).

\section{Conclusion}

Genomic DNA demethylation was closely related to soybean adaptability to the continuous cropping comprehensive stress, which was further verified by the increased expression of DNA demethylases ROS1 and DML. The demethylation of $\mathrm{mCpG}$ and $\mathrm{mCpHpG}$ (mCpApG preferred) contexts was more important, which mainly 
occurred in gene-regulatory regions at whole-chromosome scale. Among the DMGs, GO annotation and KEGG pathway analysis further demonstrated that various stress responders generated through strengthened glucose catabolism, amino acid and fatty acid anabolism, as well as fidelity transmission of genetic information, played important roles in soybean adaptability to this kind of adversity.

\section{Methods}

\section{Plant materials and growing conditions}

The soybean cultivars used in this study included the continuous cropping-tolerant variety KX2 (breeding and provision by Daqing Branch of Heilongjiang Academy of Agriculture Science) and continuous croppingsensitive variety HF55 (provision by Genetic Breeding Laboratory of Agricultural College of Heilongjiang Bayi Agricultural University; breeding by Hejiang Institute of Agricultural Sciences, Heilongjiang Academy of Agricultural Sciences). Continuous cropping soil was collected from Lindian County, Heilongjiang Province, China, where soybean has been cultivated continuously for 6 years. The control included neighbouring non-continuous cropping soil with physicochemical properties and fertility similar to those of the continuous cropping soil. Soybean seeds were planted in pots (diameter $25 \mathrm{~cm}$, depth $20 \mathrm{~cm}$ ) filled with continuous cropping or control soil and exposed to 25/18 ${ }^{\circ} \mathrm{C}$ (day/night) and 70\% relative humidity for 60 days in a greenhouse. Light, temperature and humidity conditions remained constant throughout the experimental periods. Soybean plants were collected carefully after 60 days of sowing. Four plants per replicate were used for measuring plant height, total leaf area and nodule number. The roots, stems, leaves and nodules of those four soybean plants were packaged in draft paper, oven-dried at $105^{\circ} \mathrm{C}$ for $30 \mathrm{~min}$, and then dried at $80^{\circ} \mathrm{C}$ to a constant weight. The total leaf area was determined through the dry weight ratio method. Chlorophyll content from leaf tissues was measured from different positions on two of the uppermost, youngest, fully expanded leaves using a portable chlorophyll content meter, CCM-200 PLUS (Opti-sciences, USA). Three repetitions per treatment were used.

\section{Whole-genome bisulfite sequencing library construction and sequencing}

Leaf material was excised from the uppermost third of the functional leaves of 60-d-old plants, frozen in liquid nitrogen and stored at $-80^{\circ} \mathrm{C}$ until DNA isolation. There were three repetitions per treatment. Genomic DNA was extracted using a QIAamp DNA Micro Kit (Qiagen, USA) according to the manufacturer's instructions. DNA concentration was quantified using a Qubit Fluorometer (Invitrogen, USA), and DNA integrity was detected by $1 \%$ agarose gel electrophoresis. After that, DNA of three repetitions was mixed in equal amounts for library construction.

For normal WGBS library construction, the DNA was fragmented to $100-300$ bp by sonication using a Bioruptor (Diagenode, Belgium), following blunt-ending, addition of $\mathrm{dA}$ to the 3 -end, and ligation of adaptors to protect against bisulfite conversion. DNA fragments were treated with sodium bisulfite using a Zymo EZ DNA Methylation-Gold kit (Zymo Research, USA). After sodium bisulfite conversion, unmethylated cytosine residues are converted to uracil, whereas 5-methylcytosine $(5 \mathrm{mC})$ remains unchanged. Fragments with different insert sizes were excised from the same lane of a $2 \%$ TAE agarose gel. Products were purified by using a QIAquick Gel Extraction kit (Qiagen, USA) and amplified by PCR. After PCR amplification, uracil residues were converted to thymine. Finally, the qualified library was sequenced using a HiSeq 2000 platform.

\section{Data analysis}

After sequencing, the raw reads were filtered by removing adaptor sequences and low-quality reads using the Illumina analysis pipeline. During this process, due to bisulfite conversion of cytosine to uracil, cytosines on the coding strand were changed to thymidines, and guanines on the template strand were changed to adenosines. Then, the clean and high-quality reads were aligned to the reference genome Phytozome v9.0 (https://genome.jgi.doe.gov/portal/pages/dynamicOrganismDownload.jsf?organism=Phytozome) using SOAP 2.20 software. Only perfectly matched reads were used for methylation analysis. Methylation level was determined by dividing the number of reads covering methylated cytosine $(\mathrm{mC})$ by the total reads covering cytosine $(\mathrm{mC} / \mathrm{C})[102,103]$. The ratio of $\mathrm{mCpG}, \mathrm{mCpHpG}$, or $\mathrm{mCpHpH}$ to total $\mathrm{mC}$ was used to calculate the proportion of $\mathrm{mCpG}, \mathrm{mCpHpG}$, or $\mathrm{mCpHpH}$ at all $\mathrm{mC}$ sites, respectively. DMRs were identified by comparing the methylation level difference in the same sliding window of genomes between continuous cropping samples and noncontinuous cropping samples. Only windows that contained at least five $\mathrm{CpG}$ (or $\mathrm{CpHpG}$ or $\mathrm{CpHpH}$ ) sequences were used, and changes in methylation level after continuous cropping stress had to be at least 2 -fold. $P$-values associated with DMRs were calculated by Fisher's exact test, and $P$ values $<0.05$ were considered significant. All adjacent differentially methylated windows were collapsed into a single DMR. Genes containing DMRs in the genebody and/or 2-kb flanking sequences were considered DMGs. GO enrichment analysis was performed using the BiNGO tool to analyse the molecular functions of DMGs. P-values $\leq 0.05$ after family-wise error rate correction were considered significantly enriched. KEGG pathways were used to analyse the 
biochemical metabolic processes that DMGs were involved in.

\section{Expression analysis of demethylase genes}

Total RNA was extracted from leaves of tolerant KX2 and sensitive HF55 soybean using an RNA extraction kit (UNIQ-10, SK1321, Sangon Biotech, China). The RNA concentration was calculated by measuring the absorbance at $260 \mathrm{~nm}$, and the purity was evaluated by the ratios of 260/280 nm and 260/230 nm using a NanoDrop spectrophotometer (NanoDrop Technologies, USA). cDNA was synthesized using RevertAid Premium Reverse Transcriptase (Thermo Scientific ${ }^{\mathrm{mm}}$ EP0733) with 6-mer random primers as recommended. The synthesized cDNA was subjected to qPCR. Specific primers were designed using Primer Premier 5.0 software (Premier Biosoft International, Palo Alto, USA) (Additional file 1: Table S4). The ACTIN gene was used as a reference gene to normalize the amount of RNA in each sample. The qPCR was performed in an ABI StepOne Plus instrument in a $20 \mu \mathrm{L}$ reaction mixture containing $2 \mu \mathrm{L}$ cDNA, $4 \mu \mathrm{mol}$ forward and reverse primers, and $10 \mu \mathrm{L}$ SybrGreen qPCR Master Mix (Takara Biotech, China). Thermal cycling conditions were as follows: pre-incubation at $95{ }^{\circ} \mathrm{C}$ for $3 \mathrm{~min}$, followed by 45 cycles of denaturation at $95^{\circ} \mathrm{C}$ for $7 \mathrm{~s}$, annealing at $57^{\circ} \mathrm{C}$ for $10 \mathrm{~s}$ and elongation at $72{ }^{\circ} \mathrm{C}$ for $15 \mathrm{~s}$. A melting curve was analysed at the end of the qPCR to verify specific amplification. The relative expression quantity was determined by the $2^{-\Delta \Delta \mathrm{Ct}}$ method, where $\Delta \mathrm{Ct}=(\mathrm{Ct}$ target gene $-\mathrm{Ct}$ actin gene $)$ and $\Delta \Delta \mathrm{Ct}=(\Delta \mathrm{Ct}$ treatment $-\Delta \mathrm{Ct}$ control $)$. The experimental data were statistically analysed with the $t$ test using SPSS software (version 25.0, SPSS Inc., USA). $P$ values lower than 0.05 were considered statistically significant.

\section{Additional file}

Additional file 1: Table S1. Morphological indexes of soybean plants under different conditions. Table S2. Effective coverage of each chromosome in each sample. Table S3. Effective coverage of various regions in each sample. Table S4. The primer sets used in qRT-PCR. Figure S1. Cumulative distribution of effective sequencing depth in total cytosine and three sequence contexts. Figure S2-1. Methylcytosine density throughout chromosome one to five in sensitive HF55 and tolerant KX2 under different conditions. Figure S2-2. Methylcytosine density throughout chromosome six to ten in sensitive HF55 and tolerant KX2 under different conditions. Figure S2-3. Methylcytosine density throughout chromosome eleven to fifteen in sensitive HF55 and tolerant KX2 under different conditions. Figure S2-4. Methylcytosine density throughout chromosome sixteen to twenty in sensitive HF55 and tolerant KX2 under different conditions. (DOCX $10182 \mathrm{~kb}$ )

\section{Abbreviations}

5mC: Cytosine methylation; ABA: Abscisic acid; CMT: Chromomethylase 3; DME: Demeter; DMGs: Differentially methylated genes; DML: Demeter-like; DMRs: Differentially methylated regions; DRM2: Domains Rearranged Methyltransferase 2; GABA: Y-aminobutyric acid; GO: Gene Ontology;
GR: Glutathione reductase; HF55: He Feng 55; JA: Jasmonic acid; KEGG: Kyoto Encyclopedia of Genes and Genomes; KX2: Kang Xian 2; MeJA: Methyl JA; MET1: DNA methyltransferase 1; NO: Nitric oxide; OPDA: 12-oxo-10,15(Z) phytodienoic acid; PCs: Phytochelatins; qRT-PCR: Real-time quantitative PCR; RdDM: RNA-directed DNA methylation; ROS: Reactive oxygen species; ROS1: Repressor of Silencing 1; SA: Salicylic acid; SAH: S-adenosylhomocysteine; siRNAs: Small interfering RNAs; WGBS: Whole-genome bisulfite sequencing

\section{Acknowledgements}

Not applicable.

\section{Fundings}

This work was supported by the National Natural Science Foundation of China [grant number 31201163]; the Science and Technology Development Program of Heilongjiang Agricultural Reclamation Department of China [grant number HNK135-02-06-06]; and PhD research startup foundation of Heilongjiang Bayi Agricultural University [XDB-2016-23]. The funding agents only provided the financial support but did not participate in the design and implementation of the experimental, analysis of data and in the writing of the manuscript.

\section{Availability of data and materials}

The datasets used and/or analyzed during the current study are available from the corresponding author on reasonable request.

\section{Authors' contributions}

$\mathrm{XL}, \mathrm{SF}$ and $\mathrm{ZD}$ conceived and designed this study. $\mathrm{XL}$, SF and $\mathrm{YH}$ wrote the paper. $Y Z$ and NF analyzed the data. JL supplied materials for experiments. $X H, J D$ and $W Z$ prepared samples for bisulfite sequencing and performed the real-time PCR test. All authors have read and approved the manuscript for publication.

Ethics approval and consent to participate

Not applicable.

\section{Consent for publication}

Not applicable.

\section{Competing interests}

The authors declare that they have no competing interests.

\section{Publisher's Note}

Springer Nature remains neutral with regard to jurisdictional claims in published maps and institutional affiliations.

\section{Author details}

${ }^{1}$ Heilongjiang Bayi Agricultural University, Daqing 163319, China. ${ }^{2}$ Daqing Branch of Heilongjiang Academy of Agriculture Science, Daqing 163316, China.

Received: 5 November 2018 Accepted: 1 February 2019 Published online: 18 February 2019

\section{References}

1. Van Dam J, Faaij AP, Hilbert J, Petruzzi H, Turkenburg W. Large-scale bioenergy production from soybeans and switchgrass in Argentina: part B. Environmental and socio-economic impacts on a regional level. Renew Sust Energ Rev. 2009;13(8):1679-709.

2. Lu S, Zhao X, Hu Y, Liu S, Nan H, Li X, Fang C, Cao D, Shi X, Kong L, et al. Natural variation at the soybean $J$ locus improves adaptation to the tropics and enhances yield. Nat Genet. 2017;49(5):773-9.

3. Kim E, Hwang S, Lee I. SoyNet: a database of co-functional networks for soybean Glycine max. Nucleic Acids Res. 2016;45(D1):D1082-9.

4. Sojneková M, Chytrý M. From arable land to species-rich semi-natural grasslands: succession in abandoned fields in a dry region of Central Europe. Ecol Eng. 2015;77:373-81.

5. Xie H, Zou J, Jiang H, Zhang N, Choi Y. Spatiotemporal pattern and driving forces of arable land-use intensity in China: toward sustainable land management using emergy analysis. Sustainability. 2014;6(6):3504-20. 
6. Zhang Q, Li Z, Han B. Immediate responses of cyst nematode, soil-borne pathogens and soybean yield to one-season crop disturbance after continuous soybean in Northeast China. Int J Plant Prod. 2013;7:341-53.

7. Liu X, Li Y, Han B, Zhang Q. Yield response of continuous soybean to oneseason crop disturbance in a previous continuous soybean field in Northest China. Field Crop Res. 2012;138:52-6.

8. Chen X, Wang Y, Li W, Wang Y, Wei D, Wang X, Han X. Impact of long-term continuous soybean cropping on ammonia oxidizing bacteria communities in the rhizosphere of soybean in Northeast China. Acta Agric Scand B-Soil Plant Sci. 2015;65(5):470-8

9. Chen X. Characterizion of microorganism community in the rhizosphere of continuous cropping soybean in black soil. Univ Chin Acad Sci. 2015;5:12.

10. Li C, Li X, Kong W, Wu Y, Wang J. Effect of monoculture soybean on soil microbial community in the Northeast China. Plant Soil. 2010;330(1-2):423-33.

11. Huang LF, Song LX, Xia XJ, Mao WH, Shi K, Zhou YH, Yu JQ. Plant-soil feedbacks and soil sickness: from mechanisms to application in agriculture. J Chem Ecol. 2013;39(2):232-42.

12. Ruan W, Zhu X, Li H, Zhang X, Guo S, Wang J, Zhang F, Gao Y. Soybean autotoxicity: effects of m-hydroxy-phenylacetic acid on cell ultrastructura changes and gene expression in soybean roots. Allelopath J. 2009;24(2):271-82.

13. Cui J, Wang Y, Han J, Cai B. Analyses of the community compositions of root rot pathogenic fungi in the soybean rhizosphere soil. Chile J Agric Res. 2016;76(2):179-87.

14. Leister D, Wang L, Kleine T. Organellar gene expression and acclimation of plants to environmental stress. Front Plant Sci. 2017;8:387.

15. Boyko A, Kovalchuk I. Epigenetic control of plant stress response. Environ Mol Mutagen. 2008;49(1):61-72

16. Verhoeven KJ, Jansen JJ, van Dijk PJ, Biere A. Stress-induced DNA methylation changes and their heritability in asexual dandelions. New Phytol. 2010;185(4):1108-18.

17. Zhang M, Kimatu JN, Xu K, Liu B. DNA cytosine methylation in plant development. J Genet Genom. 2010;37(1):1-12.

18. Hewezi T. Editorial: epigenetic regulation of plant development and stress responses. Plant Cell Rep. 2017;37(1):1-2.

19. Ganguly DR, Crisp PA, Eichten SR, Pogson BJ. The Arabidopsis DNA methylome is mtable under transgenerational drought stress. Plant Physiol. 2017;175(4):1893-912.

20. Lang Z, Lei M, Wang X, Tang K, Miki D, Zhang H, Mangrauthia SK, Liu W, Nie W, Ma G, et al. The methyl-CpG-binding protein MBD7 facilitates active DNA demethylation to limit DNA hyper-methylation and transcriptional gene silencing. Mol Cell. 2015;57(6):971-83.

21. He XJ, Chen T, Zhu JK. Regulation and function of DNA methylation in plants and animals. Cell Res. 2011;21(3):442-65.

22. Matzke MA, Mosher RA. RNA-directed DNA methylation: an epigenetic pathway of increasing complexity. Nat Rev Genet. 2014;15(6):394-408.

23. Zhu JK. Active DNA demethylation mediated by DNA glycosylases. Annu Rev Genet. 2009:43:143-66.

24. Park J, Frost J, Park K, Ohr H, Park G, Kim S, Eom H, Lee I, Brooks J, Fischer R, et al. Control of DEMETER DNA demethylase gene transcription in male and female gamete companion cells in Arabidopsis thaliana. Proc Natl Acad Sci. 2017;114(8):2078-83.

25. Agius F, Kapoor A, Zhu J. Role of the Arabidopsis DNA glycosylase/lyase ROS1 in active DNA demethylation. Proc Natl Acad Sci. 2006;103(31): 11796-801.

26. Morales-Ruiz T, Ortega-Galisteo A, Ponferrada-Marín M, Martínez-Macías M, Ariza R, Roldán-Arjona T. Demeter and repressor of silencing 1 encode 5methylcytosine DNA glycosylases. Proc Natl Acad Sci. 2006;103(18):6853-8,

27. Gehring M, Huh JH, Hsieh TF, Penterman J, Choi Y, Harada JJ, Goldberg RB, Fischer RL. DEMETER DNA glycosylase establishes MEDEA polycomb gene self-imprinting by allele-specific demethylation. Cell. 2006;124(3):495-506.

28. Lang Z, Wang Y, Tang K, Tang D, Datsenka T, Cheng J, Zhang Y, Handa AK Zhu JK. Critical roles of DNA demethylation in the activation of ripeninginduced genes and inhibition of ripening-repressed genes in tomato fruit. Proc Natl Acad Sci. 2017:114(22):E4511-9.

29. Viggiano $L$, de Pinto $M$ : Dynamic DNA methylation patterns in stress response. Plant Epigenetics Springer, Cham 2017:281-302.

30. Yaish MW, Al-Lawati A, Al-Harrasi I, Patankar HV. Genome-wide DNA methylation analysis in response to salinity in the model plant caliph medic (Medicago truncatula). BMC Genomics. 2018;19(1):78.

31. Secco D, Whelan J, Rouached H, Lister R. Nutrient stress-induced chromatin changes in plants. Curr Opin Plant Biol. 2017;39:1-7.
32. Dowen RH, Pelizzola M, Schmitz RJ, Lister R, Dowen JM, Nery JR, Dixon JE, Ecker JR. Widespread dynamic DNA methylation in response to biotic stress. Proc Natl Acad Sci. 2012;109(32):E2183-91.

33. Choi CS, Sano H. Abiotic-stress induces demethylation and transcriptional activation of a gene encoding a glycerophosphodiesterase-like protein in tobacco plants. Mol Gen Genomics. 2007;277(5):589-600.

34. Wang WS, Pan YJ, Zhao XQ, Dwivedi D, Zhu LH, Ali J, Fu BY, Li ZK. Droughtinduced site-specific DNA methylation and its association with drought tolerance in rice (Oryza sativa L.). J Exp Bot. 2011;62(6):1951-60.

35. Steward N, Ito M, Yamaguchi Y, Koizumi N, Sano H. Periodic DNA methylation in maize nucleosomes and demethylation by environmental stress. J Biol Chem. 2002;277(40):37741-6.

36. Pandey G, Yadav CB, Sahu PP, Muthamilarasan M, Prasad M. Salinity induced differential methylation patterns in contrasting cultivars of foxtail millet (Setaria italica L.). Plant Cell Rep. 2017:36(5):759-72.

37. Harris RA, Wang T, Coarfa C, Nagarajan RP, Hong C, Downey SL, Johnson BE, Fouse SD, Delaney A, Zhao Y, et al. Comparison of sequencing-based methods to profile DNA methylation and identification of monoallelic epigenetic modifications. Nat Biotechnol. 2010;28(10):1097-105.

38. Adey A, Shendure J. Ultra-low-input, tagmentation-based whole-genome bisulfite sequencing. Genome Res. 2012;22(6):1139-43.

39. Henderson IR, Jacobsen SE. Epigenetic inheritance in plants. Nature. 2007; 447(7143):418-24.

40. Vanyushin B, Ashapkin V. DNA methylation in higher plants: past, present and future. Biochi Biophys Acta Gene Regul Mech. 2011;1809(8):360-8.

41. McClean PE, Mamidi S, McConnell M, Chikara S, Lee R. Synteny mapping between common bean and soybean reveals extensive blocks of shared loci. BMC Genomics. 2010;11(1):184.

42. Lukens $L N$, Zhan S. The plant genome's methylation status and response to stress: implications for plant improvement. Curr Opin Plant Biol. 2007;10(3):317-22.

43. Chinnusamy V, Zhu J-K. Epigenetic regulation of stress responses in plants. Curr Opin Plant Biol. 2009:12(2):133-9.

44. Li X, Zhu JD, Hu FY, Ge S, Ye M. Single-base resolution maps of cultivated and wild rice methylomes and regulatory roles of DNA methylation in plant gene expression. BMC Genomics. 2012;13(1):300.

45. Lister R, O'Malley RC, Tonti-Filippini J, Gregory BD, Berry CC, Millar AH, Ecker $J R$. Highly integrated single-base resolution maps of the epigenome in Arabidopsis. Cell. 2008;133:523-36.

46. Wada Y, Miyamoto K, Kusano T, Sano H. Association between up-regulation of stress-responsive genes and hypomethylation of genomic DNA in tobacco plants. Mol Gen Genomics. 2004;271(6):658-66.

47. Lippman Z, Gendrel A-V, Black M, Vaughn MW, Dedhia N, McCombie WR, Lavine K, Mittal V, May B, Kasschau KD. Role of transposable elements in heterochromatin and epigenetic control. Nature. 2004;430(6998):471-6.

48. Jaenisch $\mathrm{R}$, Bird $\mathrm{A}$. Epigenetic regulation of gene expression: how the genome integrates intrinsic and environmental signals. Nat Genet. 2003; 33(Suppl):245-54

49. Deleris A, Halter T, Navarro L. DNA methylation and demethylation in plant immunity. Annu Rev Phytopathol. 2016:54:579-603.

50. Boyko A, Kathiria P, Zemp FJ, Yao Y, Pogribny I, Kovalchuk I. Transgenerational changes in the genome stability and methylation in pathogen-infected plants: (virus-induced plant genome instability). Nucleic Acids Res. 2007:35(5):1714-25.

51. Ferreira LJ, Azevedo V, Maroco J, Oliveira MM, Santos AP. Salt tolerant and sensitive rice varieties display differential methylome flexibility under salt stress. PLoS One. 2015;10(5):e0124060

52. Bocchini M, Bartucca ML, Ciancaleoni S, Mimmo T, Cesco S, Pii Y, Albertini E, Del Buono D. Iron deficiency in barley plants: phytosiderophore release, iron translocation, and DNA methylation. Front Plant Sci. 2015;6:514.

53. Labra M, Ghiani A, Citterio S, Sgorbati S, Sala F, Vannini C, Ruffini-Castiglione M, Bracale M. Analysis of cytosine methylation pattern in response to water deficit in pea root tips. Plant Biol. 2002;4(6):694-9.

54. Kovar A, Koukalova B, Bezde M, Opatrn Z. Hypermethylation of tobacco heterochromatic loci in response to osmotic stress. Theor Appl Genet. 1997; 95(1-2):301-6

55. Sabbah S, Raise M, Tal M. Methylation of DNA in NaCl-adapted cells of potato. Plant Cell Rep. 1995;14(7):467-70.

56. Varriale A. DNA methylation in plants and its implications in development, hybrid vigour, and evolution. Plant Epigenetics. Cham: Springer; 2017. p. 263-80.

57. Takuno S, Ran J, Gaut B. Evolutionary patterns of genic DNA methylation vary across land plants. Nat Plants. 2016;2:15222. 
58. Patil V, Ward RL, Hesson LB. The evidence for functional non-CpG methylation in mammalian cells. Epigenetics. 2014;9(6):823-8.

59. Zhu J, Kapoor A, Sridhar W, Agius F, Zhu JK. The DNA glycosylase/lyase ROS1 functions in pruning DNA methylation patterns in Arabidopsis. Curr Biol. 2007;17(1):54-9.

60. Drohat AC, Coey CT. Role of base excision "repair" enzymes in erasing epigenetic marks from DNA. Chem Rev. 2016;116(20):12711-29.

61. Vaquero-Sedas MI, Gamez-Arjona FM, Vega-Palas MA. Arabidopsis thaliana telomeres exhibit euchromatic features. Nucleic Acids Res. 2011;39(6):2007-17.

62. Vega-Vaquero A, Bonora G, Morselli M, Vaquero-Sedas MI, Rubbi L, Pellegrini $M$, Vega-Palas M. Novel features of telomere biology revealed by the absence of telomeric DNA methylation. Genome Res. 2016;26(8):1047-56.

63. Guo W, Fiziev P, Yan W, Cokus S, Sun X, Zhang MQ, Chen P-Y, Pellegrini M BS-Seeker2: a versatile aligning pipeline for bisulfite sequencing data. BMC Genomics. 2013:14(1):774.

64. Fernández S, Eritja R, Aviñó A, Jaumot J, Gargallo R. Influence of pH, temperature and the cationic porphyrin TMPyP4 on the stability of the i-motif formed by the 5'-(C 3 TA 2) 4-3' sequence of the human telomere. Int J Biol Macromol. 2011;49(4):729-36.

65. Schoeftner S, Blasco MA. A 'higher order' of telomere regulation: telomere heterochromatin and telomeric RNAs. EMBO J. 2009;28(16):2323-36.

66. Du J, Johnson LM, Jacobsen SE, Patel DJ. DNA methylation pathways and their crosstalk with histone methylation. Nat Rev Mol Cell Biol. 2015;16(9): 519-32.

67. Guo JU, Su Y, Shin JH, Shin J, Li H, Xie B, Zhong C, Hu S, Le T, Fan G, et al. Distribution, recognition and regulation of non- $C p G$ methylation in the adult mammalian brain. Nat Neurosci. 2014;17(2):215-22.

68. Cokus SJ, Feng S, Zhang X, Chen Z, Merriman B, Haudenschild CD, Pradhan S, Nelson SF, Pellegrini M, Jacobsen SE. Shotgun bisulphite sequencing of the Arabidopsis genome reveals DNA methylation patterning. Nature. 2008; 452(7184):215-9.

69. Gruenbaum Y, Naveh-Many T, Cedar H, Razin A. Sequence specificity of methylation in higher plant DNA. Nature. 1981;292(5826):860-2.

70. Pelizzola M, Ecker JR. The DNA methylome. FEBS Lett. 2011;585(13):1994-2000.

71. Ramsahoye BH, Biniszkiewicz D, Lyko F, Clark V, Bird AP, Jaenisch R. Non-CpG methylation is prevalent in embryonic stem cells and may be mediated by DNA methyltransferase 3a. Proc Natl Acad Sci. 2000;97(10):5237-42.

72. Plaxton WC. The organization and regulation of plant glycolysis. Annu Rev Plant Biol. 1996:47:185-214.

73. Seth CS, Remans T, Keunen E, Jozefczak M, Gielen H, Opdenakker K, Weyens N, Vangronsveld J, Cuypers A. Phytoextraction of toxic metals: a central role for glutathione. Plant Cell Environ. 2012;35(2):334-46.

74. Noctor G, Mhamdi A, Chaouch S, Han Y, Neukermans J, Marquez-Garcia B, Queval G, Foyer CH. Glutathione in plants: an integrated overview. Plant Cell Environ. 2012;35(2):454-84.

75. Foyer $\mathrm{CH}$, Shigeoka S. Understanding oxidative stress and antioxidant functions to enhance photosynthesis. Plant Physiol. 2011;155(1):93-100.

76. Nazar R, lqbal N, Syeed S, Khan N. Salicylic acid alleviates decreases in photosynthesis under salt stress by enhancing nitrogen and sulfur assimilation and antioxidant metabolism differentially in two mungbean cultivars. J Plant Physiol. 2011;168(8):807-15.

77. Pál M, Kovács V, Szalai G, Soós V, Ma X, Liu H, Mei H, Janda T. Salicylic acid and abiotic stress responses in rice. J Agron Crop Sci. 2014:200(1):1-11.

78. Capaldi FR, Gratão PL, Reis AR, Lima LW, Azevedo RA. Sulfur metabolism and stress defense responses in plants. Trop Plant Biol. 2015;8(3-4):60-73.

79. Lu SC. S-adenosylmethionine. Int J Biochem Cell Biol. 2000;32(4):391-5.

80. Fuso A, Seminara L, Cavallaro RA, D'Anselmi F, Scarpa S. Sadenosylmethionine/homocysteine cycle alterations modify DNA methylation status with consequent deregulation of PS1 and BACE and beta-amyloid production. Mol Cell Neurosci. 2005;28(1):195-204.

81. Marco F, Alcazar R, Tiburcio AF, Carrasco P. Interactions between polyamines and abiotic stress pathway responses unraveled by transcriptome analysis of polyamine overproducers. OMICS. 2011;15(11):775-81.

82. Tiburcio AF, Altabella T, Bitrián M, Alcázar R. The roles of polyamines during the lifespan of plants: from development to stress. Planta. 2014;240(1):1-18.

83. Pathak MR, Teixeira da Silva JA, Wani SH. Polyamines in response to abiotic stress tolerance through transgenic approaches. GM Crops Food. 2014;5(2):87-96.

84. Minocha R, Majumdar R, Minocha SC. Polyamines and abiotic stress in plants: a complex relationship. Front Plant Sci. 2014;5:175.

85. Gupta K, Dey A, Gupta B. Plant polyamines in abiotic stress responses. Acta Physiol Plant. 2013;35(7):2015-36
86. Majumdar R, Barchi B, Turlapati SA, Gagne M, Minocha R, Long S, Minocha SC. Glutamate, ornithine, arginine, proline, and polyamine metabolic interactions: the pathway is regulated at the post-transcriptional level. Front Plant Sci. 2016:7:78.

87. Akcay N, Bor M, Karabudak T, Ozdemir F, Turkan I. Contribution of gamma amino butyric acid (GABA) to salt stress responses of Nicotiana sylvestris CMSII mutant and wild type plants. J Plant Physiol. 2012;169(5):452-8.

88. Hussain SS, Ali M, Ahmad M, Siddique K. Polyamines: natural and engineered abiotic and biotic stress tolerance in plants. Biotechnol Adv. 2011;29(3):300-11.

89. Bitrian M, Zarza X, Altabella T, Tiburcio AF, Alcazar R. Polyamines under abiotic stress: metabolic crossroads and hormonal crosstalks in plants. Metabolites. 2012;2(3):516-28.

90. Winter G, Todd CD, Trovato M, Forlani G, Funck D. Physiological implications of arginine metabolism in plants. Front Plant Sci. 2015;6:534.

91. Domingos P, Prado AM, Wong A, Gehring C, Feijo JA. Nitric oxide: a multitasked signaling gas in plants. Mol Plant. 2015;8(4):506-20.

92. Beisson F, Li Y, Bonaventure G, Pollard M, Ohlrogge JB. The acyltransferase GPAT5 is required for the synthesis of suberin in seed coat and root of Arabidopsis. Plant Cell. 2007;19(1):351-68.

93. Upchurch RG. Fatty acid unsaturation, mobilization, and regulation in the response of plants to stress. Biotechnol Lett. 2008;30(6):967-77.

94. Kachroo A, Kachroo P. Fatty acid-derived signals in plant defense. Annu Rev Phytopathol. 2009:47:153-76.

95. Creelman RA, Mulpuri R. The oxylipin pathway in Arabidopsis. Arabidopsis Book. 2002;1:e0012.

96. Tuteja N, Ahmad P, Panda BB, Tuteja R. Genotoxic stress in plants: shedding light on DNA damage, repair and DNA repair helicases. Mutat Res. 2009; 681(2-3):134-49.

97. Balestrazzi A, Confalonieri M, Macovei A, Dona M, Carbonera D. Genotoxic stress, DNA repair, and crop productivity. In: Tuteja N, Gill SS, editors. Crop improvement under adverse conditions. Berlin: Springer; 2012. p. 153-70.

98. Filichkin S, Priest HD, Megraw M, Mockler TC. Alternative splicing in plants: directing traffic at the crossroads of adaptation and environmental stress. Curr Opin Plant Biol. 2015;24:125-35.

99. Liu JX, Howell SH. Endoplasmic reticulum protein quality control and its relationship to environmental stress responses in plants. Plant Cell. 2010; 22(9):2930-42.

100. Nakaminami K, Matsui A, Shinozaki K, Seki M. RNA regulation in plant abiotic stress responses. Biochim Biophys Acta Gene Regul Mech. 2012;1819(2):149-53.

101. Howell SH. Endoplasmic reticulum stress responses in plants. Annu Rev Plant Biol. 2013:64:477-99.

102. Xiang H, Zhu J, Chen Q, Dai F, Li X, Li M, Zhang H, Zhang G, Li D, Dong Y. Single base-resolution methylome of the silkworm reveals a sparse epigenomic map. Nat Biotechnol. 2010;28(5):516-20.

103. Lister R, Pelizzola M, Dowen RH, Hawkins RD, Hon G, Tonti-Filippini J, Nery JR, Lee L, Ye Z, Ngo QM. Human DNA methylomes at base resolution show widespread epigenomic differences. Nature. 2009:462(7271):315-22.

\section{Ready to submit your research? Choose BMC and benefit from:}

- fast, convenient online submission

- thorough peer review by experienced researchers in your field

- rapid publication on acceptance

- support for research data, including large and complex data types

- gold Open Access which fosters wider collaboration and increased citations

- maximum visibility for your research: over $100 \mathrm{M}$ website views per year

At BMC, research is always in progress.

Learn more biomedcentral.com/submission 